\title{
EVIDENCE THAT STOCK PRICES DO NOT FULLY REFLECT THE IMPLICATIONS OF CURRENT EARNINGS FOR FUTURE EARNINGS*
}

\author{
Victor L. BERNARD \\ Harvard Business School, Boston, MA 02163, USA \\ University of Michigan, Ann Arbor, MI 48109, USA \\ Jacob K. THOMAS \\ Columbia University, New York, NY 10027, USA
}

Received May 1990, final version received December 1990

\begin{abstract}
Evidence presented here is consistent with a failure of stock prices to rcflect fully the implications of current earnings for future earnings. Specifically, the three-day price reactions to announcements of earnings for quarters $t+1$ through $t+4$ are predictable, based on earnings of quarter $t$. Even more surprisingly, the signs and magnitudes of the three-day reactions are related to the autocorrelation structure of earnings, as if stock prices fail to reflect the extent to which each firm's earnings series differs from a seasonal random walk.
\end{abstract}

\section{Introduction}

Several studies have documented that estimated abnormal returns are predictable, based on previously-announced earnings [e.g., Ball and Brown (1968), Joy, Litzenberger, and McEnally (1977), Watts (1978), Rendleman, Jones, and Latane (1982), and Foster, Olsen, and Shevlin (1984)]. Repeated attempts to explain this 'post-earnings-announcement drift' as a product of research design flaws, including failure to adjust abnormal returns fully for

\footnotetext{
*We would like to acknowledge Thomas Lys, the referee, whose suggestions led to substantive improvements in the paper. We are grateful to Jim Wahlen for his research assistance and suggestions, and to Harry DeAngelo, Charles Jones, and members of Prudential Bache's Quantitative Research department, who helped plant the seeds that led to this research. We also appreciate comments received from Ray Ball, Robert Bowen, Michael Brennan, Larry Brown, Susan Chaplinsky, Gene Fama, Mark Grinblatt, Gautam Kaul, Han Kim, S.P. Kothari, Gene Imhoff, Maurice Joy, Robert Freeman, Robert Lipe, Jim McKeown, Pat O'Brien, Gordon Richardson, Jay Ritter, Michael Salinger, Nejat Seyhun, Doug Skinner, Ross Watts (the editor), and other participants in workshops at Baruch College, Columbia University, Florida State University, Harvard Business School, M.I.T., Notre Dame, Penn State University, and the Universities of Colorado, Illinois, Kansas, Michigan, Rochester, Southern California, and South Carolina. Victor Bernard is grateful for the support of the Price Waterhouse Foundation.
} 
risk, have failed to resolve the anomaly. ${ }^{1}$ Bernard and Thomas (1989) describe an implementable strategy, based upon the anomaly, that produces an estimated annualized abnormal return of 18 percent (before transactions costs) during the first quarter subsequent to the earnings announcement. Smaller abnormal returns appear to persist for at least two additional quarters.

It is difficult to understand why stock prices would appear not to respond completely and immediately to information as visible and freely available as publicly announced earnings. Although they do not purport to identify the reason for post-announcement drift, Bernard and Thomas (1989) and Freeman and Tse (1989) do provide one clue that could aid in the pursuit for an explanation. Specifically, they find that a disproportionately large fraction of the post-announcement drift is 'delayed' until the subsequent quarter's earnings anncuncement. In other words, given that a firm announces positive (negative) unexpected earnings for quarter $t$, the market tends to be positively (negatively) surprised in the days surrounding the announcement for quarter $t+1$. As Bernard and Thomas note, the evidence is consistent with a market that 'fails to adequately revise its expectations for quarter $t+1$ earnings upon receipt of the news for quarter $t^{\prime}$ (p. 27).

This paper investigates the possibility that stock prices fail to reflect fully the implications of current earnings for future earnings. Specifically, we entertain the hypothesis that prices fail to reflect the extent to which the time-series behavior of earnings deviates from a naive expectation: a seasonal random walk, where expected earnings are simply earnings for the corresponding quarter from the previous year. ${ }^{2}$ It is well known that earnings

\footnotetext{
'A battery of tests in Bernard and Thomas (1989, p. 34) produces evidence that cannot plausibly be reconciled with arguments built on risk mismeasurement'. Specifically, Bernard and Thomas show that (1) contrary to the prediction of Ball, Kothari, and Watts (1988) shifts in beta are far too small to explain the drift; (2) five other measures of risk identified in the arbitrage pricing literature fail to explain the drift; (3) there is no evidence of any other (unidentified) risk surfacing in the form of a loss - that is, returns to a zero-investment trading strategy are consistently positive over time; and (4) in violation of plausible predictions of capital asset pricing theory as they would apply to a broad cross-section of stocks, the mean raw (total) post-announcement returns on 'bad news' stocks are significantly less than Treasury bill rates. Both Bernard and Thomas (1989) and Foster, Olsen, and Shevlin (1984) also cast doubt on the viability of other explanations based on potential research design flaws, such as various forms of hindsight bias, survivorship bias, and biases in return calculations.

${ }^{2}$ We are not the first to consider this possibility. That credit goes to Rendleman. Jones, and Latane (1987), who showed that when one controls for quarter $t+1$ earnings, much of the drift associated with quarter $t$ earnings is eliminated. They conclude that post-announcement drift can be explained in part as a predictable response to the subsequent earnings announcement. However, since that study focuses on abnormal returns measured over long windows, it is difficult to rule out alternative explanations for the results (e.g., certain risk-based arguments). Freeman and Tse (1989) document (1) the predictability of the short-window response to quarter $t+1$ earnings that is also documented in Bernard and Thomas (1989) and (2) that when one controls for the effect of quarter $t+1$ earnings at least half of the drift associated with quarter $t$ earnings is eliminated. On that basis, they conclude that 'the time-series behavior of earnings
} 
forecast errors based on such a naive model are correlated through time [see, for example, Freeman and Tse (1989)]. In contrast, in a market that fully impounds all prior earnings information, forecast errors should not be autocorrelated (by definition). What we study here is the possibility that market prices can be modeled partially as reflections of naive expectations, and that as a result, the reactions of prices to future earnings are predictable, just as the forecast errors of a naive expectation model are predictable.

Our results are surprisingly consistent with this depiction of stock-price behavior. By assuming that stock prices are at least partially influenced by the above naive earnings expectation, we are able to predict with a significant degree of accuracy the three-day reaction to fuiture earnings announcements (up to four quarters ahead), given only current earnings and information about the (historical) time-series behavior of earnings. Moreover, we can relate not only the signs but the relative magnitudes of the future reactions to the autocorrelation structure of forecast errors based on the naive seasonal random-walk earnings expectation.

One of the most surprising aspects of our evidence pertains to our predictions of market reactions four quarters ahead. In contrast to the well-documented positive relation between uncxpected earnings for quarter $t$ and post-announcement drift for quarter $t+1$, we find a negatice relation between unexpected earnings of quarter $t$ and the abnormal returns around the announcement of earnings for quarter $t+4$. This finding would not be predicted by any existing explanations for post-announcement drift based on concerns about potential research design flaws. However, this pattern in the data is precisely what would be expected if the prices failed to reflect fully that, while seasonally-differenced earnings are positicely correlated for adjacent quarters, they are negaticely correlated four quarters apart. That is, the data behave as if the market is consistently surprised that a portion of an earnings change tends to be reversed four quarters later.

A stock market in which prices are influenced by traders who anchor on a comparison of year-to-year changes in quarterly earnings, much like the financial press does in its coverage of earnings announcements (e.g., the Wall Street Journal's Digest of Earnings Reports), represents a disturbing departure from what would be predicted by existing models of efficient markets. For zero-investment portfolios constructed on the basis of the historical time-series behavior of earnings, the indicated abnormal returns from the day after the earnings announcement through the subsequent earnings announcement are approximately 8 to 9 percent, or 35 percent on an annualized basis, before transactions costs. Even higher abnormal returns per unit time (67

provides a partial explanation of the drift phenomenon'. However, that possibility was not the main focus of the Freeman and Tse paper, and thus they did not draw the links between post-announcement drift and the time-series properties of earnings that are documented here. 
percent on an annualized basis) are available for portfolios constructed 15 days prior to the expected date for the upcoming announcement and held through the announcement.

The evidence in this paper offers two main contributions beyond the previous literature on post-announcement drift. First, the paper relates the signs and magnitudes of reactions to subsequent earnings announcements to the historical autocorrelation structure of earnings; this linkage may help identify the cause of post-announcement drift. Second, the evidence as a whole creates several added obstacles to contentions that the drift might ultimately be explained by errors in the methodology used to estimate expected returns. For example, an explanation based on failure to control for risk would now have to argue that 'good-news' firms experience 'delayed' increases in risk over three-day intervals that coincide with each of the next three earnings announcements, and then a decrease in risk over the three-day interval coinciding with the fourth subsequent announcement. The converse would have to hold for 'bad-news' firms. At a minimum, any rationale for such behavior must have a more complex structure than explanations suggested to date.

The nature of the evidence in this paper is also distinct in an important way from that in the growing body of other studies that question semi-strong or weak-form market efficiency [e.g., Ou and Penman (1989a, b), Poterba and Summers (1988)]. While such studies conclude that discrepancies appear to exist between stock prices and underlying fundamentals, they make only vague predictions about when the discrepancies will be eliminated and associated abnormal returns realized. In contrast, our assumption about earnings expectations allows us to successfully predict within days the timing of subsequent abnormal returns. By linking what appears to be the elimination of a discrepancy between prices and fundamentals to prespecified information events, the study presents perhaps the most direct evidence to date that a market-efficiency anomaly is rooted in a failure of information to flow completely into price. The evidence also emphasizes that even in a market where prices fail to reflect all available information, one can still observe unusual stock-price activity concentrated around news releases. The puzzling question is, if a portion of the 'news' became predictable months earlier, why did the associated price movements not occur then?

The rest of the paper is organized as follows. In section 2, we review the time-series behavior of earnings and develop hypotheses about how stock prices would behave if the earnings expectations embedded in such prices failed to reflect fully those time-series properties. Section 3 includes tests of those hypotheses. Questions raised by the evidence and potential alternative explanations for the results are discussed in section 4 . We discuss the links between this and other research in section 5 , and offer concluding remarks in section 6 . 


\section{Hypothesis development}

\subsection{Time-series properties of quarterly earnings}

Several studies have documented the time-series behavior of quarterly earnings [e.g., Watts (1975), Foster (1977), Griffin (1977), Brown and Rozeff (1979), Bathke and Lorek (1984), Brown, Hagerman, Griffin, and Zmijewski (1987)]. The cumulative evidence indicates that seasonal differences in quarterly earnings are correlated, and that the pattern of correlations can be viewed as including two components. First, there is a positive correlation between seasonal differences that is strongest for adjacent quarters, but that remains positive over the first three lags. Thus, a change in earnings of quarter $t$ (relative to the comparable quarter of the prior year) tends to be followed by progressively smaller changes of the same sign in quarters $t+1$, $t+2$, and $t+3$. Second, there is a negative correlation between seasonal differences that are four quarters apart. That is, a portion of the change for quarter $t$ is 'reversed' in quarter $t+4$.

To offer a more specific description of the time-series behavior of earnings, table 1 presents summary statistics for the sample to be studied here, which is based on the sample used in Bernard and Thomas (1989). ${ }^{3}$ The earnings number used is net income before extraordinary items and discontinued items (item 8 from the quarterly Compustat tape). Panel A confirms that, consistent with prior research, the autocorrelations at the first three lags are positive but declining; the sample means of autocorrelations estimated separately for each firm are $0.34,0.19$, and 0.06 for lags 1,2 , and 3 , respectively. Also consistent with prior research, there is a negative autocorrelation at the fourth lag (mean $=-0.24$ ). Beyond the fourth lag, the mean autocorrelations remain negative, but much smaller: $-0.08,-0.07,-0.07,-0.06$ for lags 5 through 8 , respectively.

To obtain an intuitive sense for the implications of these autocorrelations, consider the following example. A firm reports quarterly earnings in year 0 of $\$ 10, \$ 10, \$ 10$, and $\$ 20$. Actual earnings for the first quarter of year 1 rise $\$ 1$, to $\$ 11$. Assuming no linear trend in earnings and that the autocorrelation structure of the firm's earnings is as depicted for the mean firm in table 1 , the

\footnotetext{
${ }^{3}$ The sample is obtained from firms listed on the 1987 edition of the daily CRSP file and also listed on any edition of the Compustat quarterly files from 1982 to 1987 . Based on earnings data beginning in 1970, we obtained estimates of unexpected earnings for 96,087 announcements over the period 1974-1986 for 2,649 firms. Abnormal returns data were available for up to 85,753 announcements, depending upon the return interval used. The number of observations reported in the tables varies across tests, depending upon factors such as the availability of measures of unexpected earnings at the specified lags and the interval over which abnormal returns are cumulated.
} 
Table 1

Time-series behavior of quarterly earnings. 2.626 firms, 1974-1986.

Panel A: Autocorrelations in seasonally differenced quarterly earnings

Lag

12

45

6

7

8

Distribution of firm-specific autocorrelations in seasonally-differenced eamings

$\begin{array}{lrrrrrrrr}\text { Mean } & 0.34 & 0.19 & 0.06 & -0.24 & -0.08 & -0.07 & -0.07 & -0.06 \\ \text { 25th percentile } & 0.14 & 0.05 & -0.10 & -0.46 & -0.26 & -0.24 & -0.24 & -0.25 \\ \text { Median } & 0.36 & 0.18 & 0.06 & -0.29 & -0.09 & -0.08 & -0.06 & -0.06 \\ \text { 75th percentile } & 0.57 & 0.35 & 0.21 & -0.07 & 0.08 & 0.08 & 0.09 & 0.11\end{array}$

Distribution of mean autocorrelations for 37 industries ${ }^{\mathrm{a}}$

Number of positive mean

$\begin{array}{lllllllll}\text { autocorrelations (out of 37) } & 37 & 37 & 35 & 0 & 5 & 8 & 6 & 7\end{array}$

$\begin{array}{lllllllll}25 \text { th percentile (of } 37 \text { means) } & 0.29 & 0.14 & 0.00 & -0.29 & -0.13 & -0.12 & -0.12 & -0.10\end{array}$

$\begin{array}{lllllllll}\text { Median (of } 37 \text { means) } & 0.35 & 0.19 & 0.07 & -0.24 & -0.09 & -0.08 & -0.08 & -0.08\end{array}$

$\begin{array}{lllllllll}\text { 75th percentile (of } 37 \text { means) } & 0.38 & 0.22 & 0.09 & -0.18 & -0.04 & -0.01 & -0.04 & -0.03\end{array}$

Mean firm-specific autocorrelations within size categories ${ }^{\mathrm{b}}$

Small (bottom 4 deciles)

Medium 2 Large (top 3 deciles)

$\begin{array}{ll}0.28 & 0.14 \\ 0.31 & 0.19\end{array}$

$\begin{array}{llll}0.03 & -0.29 & -0.09 & -0.08\end{array}$

$\begin{array}{ll}0.36 & 0.20\end{array}$

$0.06-0.20$

$-0.07$

$-0.08$

$-0.06-0.04$

Panel B: Autocorrelations in seasonally-differenced earnings and standardized unexpected earnings $(S U E)^{\mathfrak{C}}$

$\begin{array}{llllllllll}\text { Lag } & 1 & 2 & 3 & 4 & 5 & 6 & 7 & 8\end{array}$

Mean of firm-specific autocorrelations

Seasonally differenced

earnings (as in panel A)

SUE $\mathbf{s}$

$\begin{array}{llllllll}0.34 & 0.19 & 0.06 & -0.24 & -0.08 & -0.07 & -0.07 & -0.06 \\ 0.40 & 0.22 & 0.06 & -0.21 & -0.10 & -0.09 & -0.09 & -0.08 \\ 0.41 & 0.23 & 0.07 & -0.18 & -0.09 & -0.09 & -0.09 & -0.08\end{array}$

SUE deciles

${ }^{\mathrm{a}}$ Mean of firm-specific autocorrelations is calculated for each industry to obtain distribution of 37 autocorrelations at each lag. Only the 37 two-digit SIC industries that contain at least 20 members are represented here.

${ }^{\mathrm{b}} \mathrm{S}$ mall, medium, and large firms are in size deciles 1 to 4,5 to 7 , and 8 to 10 , respectively, based on January 1 market values of equity for NYSE-AMEX firms.

'SUEs are forecast errors from a seasonal random walk with trend, scaled by their standard deviation within the trend estimation period (up to 36 observations). SUE deciles are based on rankings within calender quarters.

expected earnings for the next four quarters would be as indicated in italics below.

$\begin{array}{lrrr} & \text { Year 0 } & \text { Year 1 } & \text { Ycar 2 } \\ \text { Quarter I } & \$ 10.00 & \$ 11.00 & \$ 10.76 \\ \text { Quarter II } & 10.00 & 10.34 & \\ \text { Quarter III } & 10.00 & 10.19 & \\ \text { Quarter IV } & 20.00 & 20.06 & \end{array}$


For the next three quarters, one would expect additional increases over the prior year level, but the amounts of the expected increases decline over the three quarters. Looking four quarters ahead to the first quarter of year 2 , we expect earnings will decline relative to this year; that is, a portion of the initial earnings change is not expected to persist.

Panel A also shows that this kind of autocorrelation pattern is quite consistent across firms. First, the pattern persists generally across the 37 two-digit SIC industries for which our sample includes 20 or more firms. For example, the signs of the within-industry means of the firm-specific autocorrelations calculated are in agreement for all 37 industries at lags 1. 2, and 4, and for 35 of 37 industries at lag 3. Second, the pattern of mean autocorrelations calculated within size categories is similar across small, medium, and large firms (those in the bottom four, middle three, and top three deciles of the NYSE/AMEX population). However, the autocorrelations over the first four lags tend to be somewhat more positive for large firms.

Panel B compares the autocorrelations in seasonally differenced earnings with those for standardized unexpected earnings (SUE), which will be a key variable in our empirical tests. The numerator of $S U E$ is equal to actual earnings minus an expectation based on a seasonal random walk with trend (where the trend is estimated using up to 36 quarters of history, if available); that is, it is simply the detrended seasonal difference in earnings. The denominator is equal to the standard deviation of this measure of unexpected earnings over the trend estimation period. To reduce the influence of outliers, SUE values greater (less) than $5(-5)$ are winsorized to $5(-5)$. The autocorrelations in $S U E$ are calculated for each firm in the sample, and a mean across firms is obtained for the autocorrelation at each lag.

The first two rows of panel B confirm that the pattern of autocorrelations in the SUEs is similar to the pattern already discussed for seasonally differenced earnings (although the magnitudes are slightly higher when SUE is the unit of analysis). The similarity indicates that the process of scaling the seasonal differences does not have a large influence on the degree of autocorrelation.

The last row of panel B presents autocorrelations in the decile assignments of $S U E \mathrm{~s}$ (based on the distribution of all $S U E \mathrm{~s}$ for a given calendar quarter), as opposed to $S U E$ s per se. These statistics are of interest because much of our subsequent analysis is based on $S U E$ deciles. As expected, the results indicate that $S U E$ deciles have time-series properties very similar to those of the SUEs.

\subsection{Hypothesis decelopment}

We now consider the behavior of stock prices in a market where earnings expectations fail to reflect the autocorrelation pattern described above. That 
is, we entertain the possibility that the earnings expectations reflected in stock prices follow a seasonal random walk with trend. ${ }^{4}$ Even though market prices may reflect less naive expectations, our goal is to develop predictions for this extreme case and then test the extent to which such predictions are supported by the data. That is, we assume that the expectation of earnings for quarter $t$ that is embedded in the market price, denoted by $\mathrm{E}^{\mathrm{M}}\left(Q_{t}\right)$, is as follows:

$$
\mathrm{E}^{\mathrm{M}}\left[Q_{t}\right]=\delta+Q_{t-4}
$$

When earnings $Q_{t}$ are announced, the market perceives the unexpected component of earnings to be $Q_{t}-\mathrm{E}^{\mathrm{M}}\left[Q_{t}\right]$. Given an 'earnings response coefficient' $\lambda$, the resulting abnormal return is

$$
A R_{t}=\lambda\left(Q_{t}-\mathrm{E}^{\mathrm{M}}\left[Q_{t}\right]\right)=\lambda\left(Q_{t}-Q_{t-4}-\delta\right) .
$$

Note that the abnormal return reflects a component equal to the current detrended seasonal difference in earnings. Thus, the abnormal return should be correlated with past detrended seasonal differences in earnings, in the same way that the current detrended seasonal difference is correlated with past detrended seasonal differences. Specifically, we hypothesize the following:

Hypothesis 1. If prices reflect an earnings expectation described by a seasonal random walk with trend, there should be positive but declining associations between the abnormal return at the announcement of quarter $t$ earnings and the detrended seasonal differences in earnings for quarters $t-1, t-2$, and $t-3$. There should be a negatice association between the abnormal return at the announcement of quarter $t$ earnings and the detrended seasonal difference in earnings for quarter $t-4$.

A useful feature of Hypothesis 1 is that it links the relation between abnormal returns and prior-period earnings data to the autocorrelation patterns presented in prior research and in table 1, and does so without the need to specify explicitly a particular model of the actual earnings process. However, the hypothesis represents a statement about the simple relation between abnormal returns and earnings changes of each prior period taken individually. If we are more precise about the actual time-series process of earnings, we can conveniently relate abnormal returns to earnings data from

\footnotetext{
${ }^{4}$ If we assume instead that the expectation is a seasonal random walk with no trend, then Hypothesis 1 below would be stated in terms of seasonal differences, before detrending. Empirical tests based on this alternative approach yield results similar to those reported here.
} 
multiple prior periods simultaneously. This, in turn, will prove useful in assessing the economic importance of the predictable component of the abnormal returns.

Based on prior research, we assume that the most accurate univariate description of the time-series process of earnings is provided by the Brown and Rozeff (1979) model, modified to include a trend term: ${ }^{5}$

$$
Q_{t}=\delta+Q_{t-4}+\phi\left(Q_{t-1}-Q_{t-5}\right)+\theta \varepsilon_{t-4}+\varepsilon_{t}
$$

where $\varepsilon_{t}$ is the white-noise earnings shock of period $t, \phi>0$, and $\theta$ is sufficiently negative to ensure that the fourth-order autocorrelation in seasonally-differenced earnings is negative.

The Brown-Rozeff model includes a first-order autoregressive term [ $\phi\left(Q_{t-1}-Q_{t-5}\right)$, which is designed to account for the positive but decaying autocorrelations in seasonally differenced earnings at lags 1 through 3 . The model also includes a seasonal moving-average term $\left(\theta \varepsilon_{t-4}\right)$ to account for the negative autocorrelation noted at the fourth lag. The earnings expectation implied by the Brown-Rozeff model is

$$
\mathrm{E}\left[Q_{t}\right]=\delta+Q_{t-4}+\phi\left(Q_{t-1}-Q_{t-5}\right)+\theta \varepsilon_{t-4}
$$

Several studies [e.g., Brown and Rozeff (1979) and Bathke and Lorek (1984)] have documented that the Brown-Rozeff model fits earnings data well and generates more accurate out-of-sample earnings forecasts than other time-series models. However, the margin of superiority is not 'large'; Bathke and Lorek (1984) find a 9 percent reduction in mean absolute percentage forecast errors when moving from a seasonal random walk with trend to the Brown-Rozeff model. Thus, even if market expectations are characterized by a seasonal random walk with trend, the resulting predictable errors in those expectations might not be substantial. Any ability to predict stock-price reactions to future earnings announcements based on past earnings and the autocorrelation structure of earnings therefore becomes that much more surprising.

\footnotetext{
${ }^{5}$ Allowing for a trend in earnings was less of a concern for Brown and Rozeff, who dealt with per-share data. We assume that the trend term equals that embedded in stock prices [eq. (1)]. This assumption simplifies the development of Hypothesis 2, without altering the thrust of our conclusions. If a difference between the trend terms does exist and it varies across firms, then the observed association (in pooled cross-section) between abnormal returns and each past seasonal difference would be more positive; the negative association at the fourth lag would arise only if $\theta$ is sufficiently negative to overcome this effect. It turns out, however, that the observed association at the fourth lag is not only negative, but consistent in terms of magnitude with predictions based on the development of Hypothesis 2. Thus the benefits of a more complex treatment of the trend term appear minimal.
} 
If the time-series process of earnings is best described by a Brown-Rozeff model, but earnings expectations embedded in prices are nevertheless based on a seasonal random walk with trend, then the abnormal return around earnings announcements presented in eq. (2) can be rewritten as shown below. We begin by decomposing the abnormal return in eq. (2) into an unpredictable component, $Q_{t}-\mathrm{E}\left[Q_{t}\right]$, and its complement, $\mathrm{E}\left[Q_{t}\right]-\mathrm{E}^{\mathrm{M}}\left[Q_{t}\right]$, that is predictable based on knowledge about the time-series behavior of earnings: ${ }^{6}$

$$
\begin{aligned}
A R_{t} & =\lambda\left(Q_{t}-\mathrm{E}^{\mathrm{M}}\left[Q_{t}\right]\right) \\
& =\lambda\left(Q_{t}-\mathrm{E}\left[Q_{t}\right]\right)+\lambda\left(\mathrm{E}\left[Q_{t}\right]-\mathrm{E}^{\mathrm{M}}\left[Q_{t}\right]\right)
\end{aligned}
$$

Relying on the Brown-Rozeff model, we can replace $\left(Q_{t}-\mathrm{E}\left[Q_{t}\right]\right)$ with the difference between eqs. (3) and (4), and replace $\left(\mathrm{E}\left[Q_{t}\right]-\mathrm{E}^{\mathrm{M}}\left[Q_{t}\right]\right)$ with the difference between eqs. (4) and (1):

$$
A R_{t}=\lambda \varepsilon_{t}+\lambda \phi\left(Q_{t-1}-Q_{t-5}\right)+\lambda \theta \varepsilon_{t-4}
$$

Since $\left(Q_{t-1}-Q_{t-5}\right)$ can be written in terms of prior period shocks, eq. (6) can also be written as

$$
\begin{aligned}
A R_{t}= & \lambda \varepsilon_{t}+\lambda \phi \varepsilon_{t-1}+\lambda \phi^{2} \varepsilon_{t-2}+\lambda \phi^{3} \varepsilon_{t-3} \\
& +\lambda\left(\theta+\phi^{4}\right) \varepsilon_{t-4}+\lambda \nu
\end{aligned}
$$

where $\nu$ is a linear combination of earnings shocks from periods prior to $t-4$, that are uncorrelated with the shocks of periods $t$ through $t-4$, and which have coefficients of order $\theta \phi$ or smaller.

Eqs. (6) and (7) provide the basis for our second hypothesis:

Hypothesis 2. If prices reflect an earnings expectation described by a seasonal random walk with trend, while the univariate times-series process of earnings is best described by the Brown-Rozeff (1979) model as written in eq. (3), then the abnormal return at the announcement of quarter $t$ earnings should have a positive partial correlation with the seasonal difference in earnings for quarter $t-1$, and a negative partial correlation with the earnings shock of period $t-4$,

\footnotetext{
${ }^{6}$ The earnings response coefficient, $\lambda$, is assumed constant across the two components of the earnings change, because the market would have no way of distinguishing between the two components given that its expectations are based on a seasonal random walk with trend. The empirical tests, however, do not rely on this assumption as we estimate unrestricted coefficients for the regression models derived from eq. (5).
} 
as specified in eq. (6). Alternatively, the abnormal return at the announcement of quarter t earnings should have positive but declining partial correlations with the earnings shocks of quarters $t-1, t-2$, and $t-3$, and a negatice partial correlation with the earnings shock of period $t-4$ as specified in eq. (7).

Note that Hypothesis 1 and Hypothesis 2 lead to tests of the same fundamental notion that prices are based on an earnings expectation that fails to reflect fully the extent to which the earnings series departs from a seasonal random walk. Hypothesis 2 is distinct from Hypothesis 1 only in that it makes a more specific assumption about the actual time-series properties of earnings. This additional assumption can potentially increase the power of our tests, as well as facilitate the construction of portfolios based on multiple prior-period earnings signals.

\section{Empirical tests}

\subsection{Portfolio tests of Hypothesis 1}

Tests of Hypothesis 1 are conducted by forming ten portfolios for each calendar quarter, based on the $S U E$ deciles of firms announcing earnings within that quarter. We then observe the relation between the SUE assignments and three-day market reactions to earnings announcements for subsequent quarters. (The three-day window includes the two days prior to and the disclosure date as reported on Compustat - from the Wall Street Journal or Dow Jones News Service.) If Hypothesis 1 is correct, then we should observe a positive relation for each of the next three announcements (but with the magnitude of the association declining over the three quarters) and a negative relation for the fourth subsequent announcement.

The measure of abnormal returns used is the same size-adjusted return described in Bernard and Thomas (1989). Daily abnormal returns for a given firm are obtained by subtracting from the total return the return on a portfolio of the NYSE/AMEX firms in the same size decile, based on January 1 market value of equity. Daily size-adjusted returns are summed across firms and cumulated over time to obtain portfolio cumulative abnormal returns.

Prior to reviewing the results, we offer one final comment on an econometric issue. Even though the primary tests focus on short (three-day) return intervals, there is some overlapping of event windows in calendar time. Thus, standard $t$-tests applied to mean abnormal returns would potentially be subject to bias due to cross-correlation in the data [see Bernard (1987)]. Therefore, for each of the major $t$-tests presented here, we also present an 'alternative $t$-test' designed by Jaffe (1974) and Fama and MacBeth (1973) to 


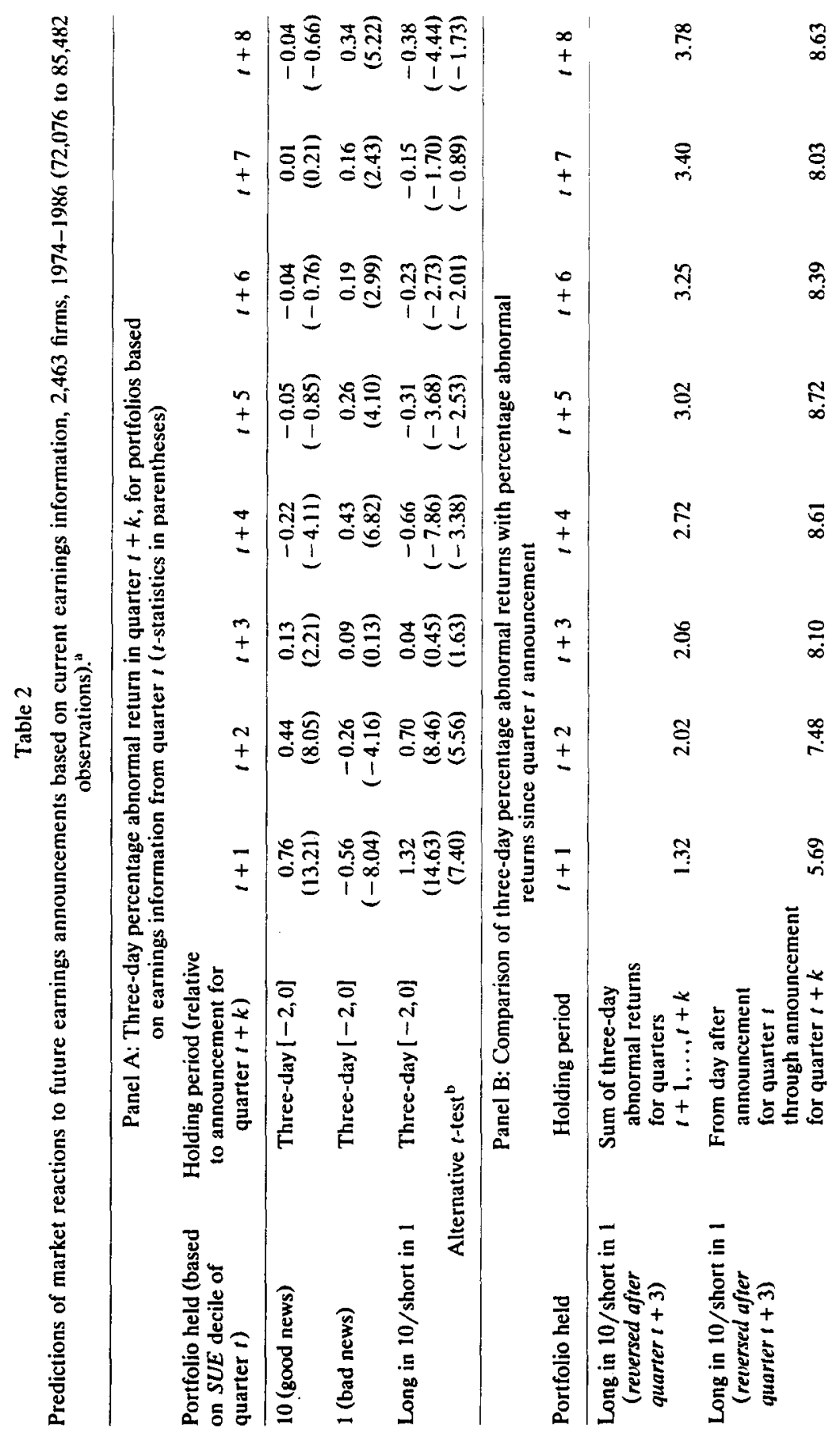




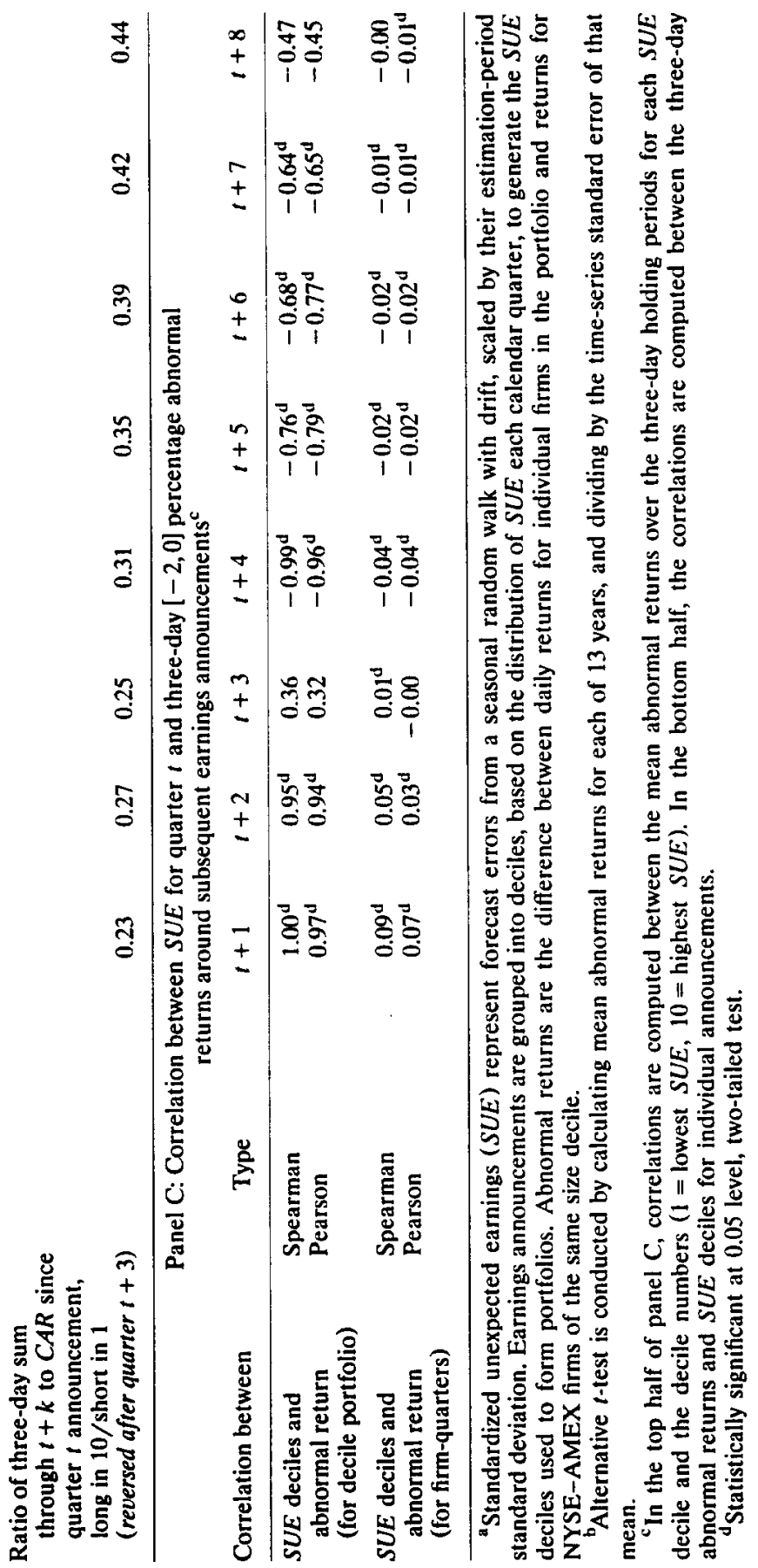


eliminate bias from cross-sectional dependence. Specifically, we calculate the value of any given portfolio return (or in the regression tests of Hypothesis 2, any given coefficient) for each of the 13 years in the database. We then compare the mean of the resulting 13 values to its time-series standard error to construct the alternative $t$-test. In most cases, this alternative calculation generates a smaller $t$-statistic, probably reflecting both a loss of power and an elimination of some bias. (The loss of power arises because equal weight is placed on data from each year, which is generally suboptimal.)

The first test of Hypothesis 1 is presented in table 2, panel A. We form portfolios that are long in extreme 'good-news' $(S U E=10)$ firms and short in 'bad-news' ( $S U E=1$ ) firms based on quarter $t$ earnings information, and then measure the mean abnormal returns for these portfolios around subsequent quarters' earnings announcements. We focus here on extreme deciles to enhance the power of our tests and provide results directly comparable to prior research. However, we later examine the behavior of all deciles.

The evidence shows that the three-day abnormal returns around earnings announcements are predictable, at least four quarters in advance. Moreover, the signs and magnitudes of the abnormal returns reflect the pattern of autocorrelations hypothesized in the previous section. The zero-investment portfolio created on the basis of quarter $t$ earnings information generates a significant positive mean abnormal return (1.32 percent) upon the announcement of quarter $t+1$ earnings, as if market prices fail to reflect fully that a given $S U E$ in quarter $t$ tends to be followed by an $S U E$ of the same sign in quarter $t+1$. As predicted, we also observe positive but smaller mean abnormal returns around the announcement of earnings for quarters $t+2$ and $t+3$. Finally, again consistent with our predictions, we observe significant negative mean abnormal returns around the announcement of earnings for quarter $t+4$, as if prices fail to reflect fully that a given earnings change in quarter $t$ is likely to be partially reversed in quarter $t+4$.

We did not offer predictions about the behavior of market reactions around earnings announcements beyond quarter $t+4$. However, based on the autocorrelations observed in table 1, we would expect small but negative market reactions to the announcements of quarters $t+5$ through $t+8$, for long (short) positions in quarter $t$ 's good-news (bad-news) firms. In fact, that is what we observe: the abnormal returns are -0.31 percent, -0.23 percent, -0.15 percent, and -0.38 percent for quarter $t+5$ through $t+8$, respectively. (The statistical significance of the last two amounts depends on the $t$-test used.) We hesitate to emphasize these particular results, however, because unlike the signs of the autocorrelations at the first four lags, the signs for lags 5 through 8 have not been robust across samples and time periods examined in prior studies [compare Foster (1977) with our evidence], and therefore might not have been predictable at the beginning of the test period. 
Table 3

Correspondence between relative magnitude of autocorrelations in earnings data and relative magnitude of abnormal returns predicted on the basis of the past earnings.

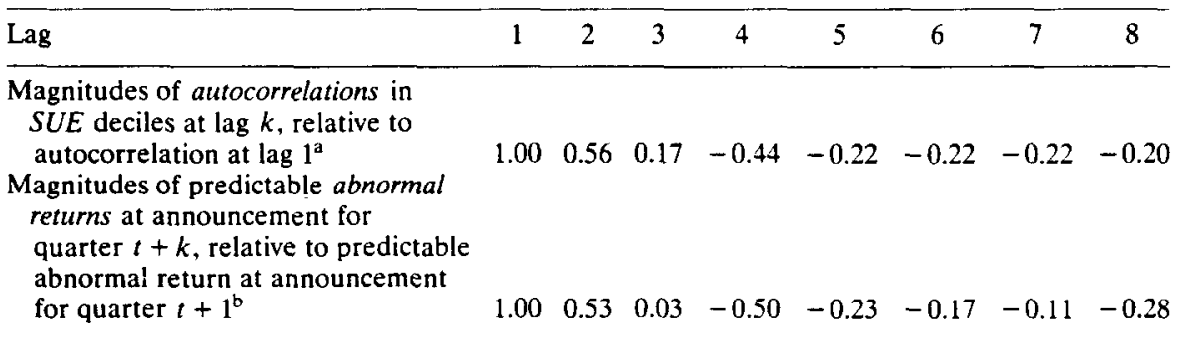

${ }^{a}$ Autocorrelations are taken from table 1, panel B, which reports means of firm-specific autocorrelations in $S U E$ deciles. Thus, the amount 0.56 shown above for lag 2 is the ratio of the mean autocorrelation in $S U E$ deciles at lag $2(0.23)$, divided by the mean autocorrelation in $S U E$ deciles at lag $1(0.41)$.

SUEs are forecast errors from a seasonal random walk with trend, scaled by their standard deviation within the trend-estimation period (up to 36 observations). SUE deciles are based on rankings within calendar quarters.

bAbnormal returns are taken from table 2, panel A, third section, which reports the return for the three-day window surrounding the announcement of earnings for quarter $t+k$, for a long position in firms with quarter $t S U E$ in decile 10, combined with a short position in firms with quarter $t S U E$ in decile 1 . Thus, the amount 0.53 shown above for lag 2 is the ratio of the abnormal return around the announcement of earnings for quarter $t+2(0.70$ percent $)$, divided by the corresponding amount for quarter $t+1$ (1.32 percent).

Hypothesis 1 is borne out in the data not only in terms of the signs of future abnormal returns, but also in terms of magnitudes. That is, the relative magnitudes of the abnormal returns around subsequent earnings announcements are in general accordance with the relative magnitudes of the autocorrelations in SUEs documented earlier. The mean autocorrelations in SUE deciles at lag $k$ (from the last row of table 1, panel B), relative to the autocorrelation at lag 1 , are shown in the first row of table 3 . They are compared with the mean abnormal returns around arnouncements for quarter $t+k$ (from the third section of table 2, panel A) relative to that for quarter $t+1$. The strength of the correspondence between the two series is striking.

Returning to table 2, panel A, we note that the predictably positive abnormal returns around the first three subsequent announcements could simply reflect evidence already documented in prior research based on longer return intervals, if the three-day abnormal returns represented a proportionate allocation of the post-announcement drift already shown to exist over six to nine months [e.g., Watts (1978), Bernard and Thomas (1989)]. To check that possibility, table 2, panel B compares the three-day abnormal returns around subsequent earnings announcements to the abnormal return cumulated over periods from the day after the announcement for quarter $t$, 
through the announcements for subsequent quarters. ${ }^{7}$ We assume a long (short) position in the good-news (bad-news) firms over the first three quarters after the earnings announcement, and then reverse that position at the teginning of the fourth subsequent quarter. The cumulative abnormal return is 5.7 percent through the announcement for quarter $t+1$ and 8.6 percent through the announcement for quarter $t+4$. The last row of panel $B$ shows that the three-day abnormal returns (summed over announcements to date) account for 23 to 31 percent of the cumulative post-announcement drift through quarter $t+4$. Given that the three-day announcement periods account for only about 5 percent of the total trading days, the announcement period reactions clearly represent a disproportionate share of the drift. This constitutes an extension of similar evidence provided by Bernard and Thomas (i989) and Freeman and Tse (1989) for the first subsequent announcement.

The evidence in table 2, panel B suggests that some portion of the post-announcement adjustment to earnings is rapid even though it is delayed. The rapid adjustments went undetected in research prior to Bernard and Thomas (1989), because subsequent earnings-announcement dates were scattered in event time. By not realigning the data at each subsequent announcement date, researchers smoothed the sharp adjustments that occur at those dates.

Table 2, panel $\mathrm{C}$ shows that the phenomenon documented above is not driven by extreme deciles; it persists throughout the sample. Panel $C$ presents the simple correlations between $S U E$ s of quarter $t$ and the three-day abnormal return surrounding each of the eight subsequent earnings announcements, at both the level of $S U E$ decile portfolios and individual firm quarters. The Spearman and Pearson correlations indicate that the relation between $S U E$ deciles for quarter $t$ and the ten corresponding mean abnormal returns around the next four earnings announcements is not only close to monotonic, but is almost perfectly linear. The sole exception is the relation for quarter $t+3$, which was not expected to be strong. Movement from analysis at the portfolio level to the level of individual firm-quarters causes the correlations to decline considerably, as expected, but the predicted pattern remains.

\footnotetext{
${ }^{7}$ While the firm's SUE is known on the day prior to the commencement of this return interval, the firm's $S U E$ decile assignment is not known until all firms have announced earnings for the quarter. Assuming the ability to calculate decile assignments prior to that time introduces a form of hindsight bias studied by Holthausen (1983). To overcome this potential bias, Foster, Olsen, and Shevlin (1984) and Bernard and Thomas (1989) assign SUEs to deciles by comparing them to the distribution of SUEs for the prior quarter. However, in this sample, the magnitude of post-announcement drift is insensitive to this adjustment.

Note that this form of hindsight bias is not an issue in the primary tests based on three-day return intervals, because by the time of the subsequent earnings announcement, the firm's SUE decile assignment would be known.
} 
A final note on table 2 concerns an apparent asymmetry in the returns for 'good-news' and 'bad-news' firms in panel A. If one simply adds announcement-period abnormal returns across the two groups, rather than offsetting long and short positions, the result is a positive abnormal return of approximately 0.20 percent, regardless of the subscquent quarter examined. That announcement-period abnormal returns are on average positive has been documented previously by Chari et al. (1988) and Ball and Kothari (1990). Why this occurs is unclear. However, note that this effect would tend to 'work against' our prediction for bad-news firms for the first three lags and good-news firms for the fourth lag, and should cancel out in our combined long and short positions. Thus, while the effect is evident in our data, it cannot explain the results of our tests.

Table 4 presents evidence like that in table 2 for firms classified as small, medium, and large (those in size deciles 1 to 4,5 to 7 , and 8 to 10 , respectively, based on January 1 market value of equity for all NYSE and AMEX firms). Fig. 1 summarizes the information from table 4 in the form of a $C A R$ plot. $^{8}$ We are motivated to partition the data by firm size because it may be more plausible that published earnings information would fail to be impounded fully in the prices of small firms relative to large firms. For example, Foster, Olsen, and Shevlin (1984) suggest that the market for information might be less well developed for small firms, thus motivating their examination of post-announcement drift as a function of firm size.

The patterns noted above are present for each size group - in every case, positive but declining abnormal returns around the announcement of earnings for quarter $t+1, t+2$, and $t+3$, and negative abnormal returns around the announcement of earnings for quarter $t+4$. However, the effects are more pronounced for small firms. Note that this cannot be attributed to differences in the time-series behavior of earnings, since there is less autocorrelation in earnings changes for small firms (table 1) and $S U E$ s actually vary less for small firms than large firms. Thus, the data are consistent with stock prices failing to reflect fully the implications of current earnings for future earnings for all firms, but the failure is more apparent for small stocks. Interestingly, however, the fraction of post-announcement drift that is delayed until subsequent earnings announcements is similar across the three size groups.

In addition to partitioning the data by firm size, we also checked the robustness of the results across fiscal quarters by partitioning on both the quarter of portfolio formation and the quarter to which the subsequent announcements pertain. The results (not reported here) are consistent across

\footnotetext{
${ }^{8}$ While Freeman and Tse (1989) present a similar plot for their overall sample (fig. 2), they offer no discussion of the reactions to announcements beyond quarter $t+1$.
} 
Table 4

Predictions of market reactions to future earnings announcements for portfolios based on current quarter's $S U E$; results by firm-size group.

\begin{tabular}{|c|c|c|c|c|}
\hline & \multicolumn{4}{|c|}{$\begin{array}{l}\text { Subsequent quarter for which } \\
\text { earnings are announced }\end{array}$} \\
\hline & $i+1$ & $1+2$ & $1+3$ & $t+4$ \\
\hline \multicolumn{5}{|c|}{ Small firms (28,877 to 30,904 observations) } \\
\hline $\begin{array}{l}\text { Abnormal return three days }[-2,0] \\
\text { around announcement, long (short) } \\
\text { in quarter t SUE decile } 10(1) \\
\text { t-statistic } \\
\text { Alternative } t \text {-test }\end{array}$ & $\begin{array}{c}1.92 \\
(8.26) \\
(4.76)\end{array}$ & $\begin{array}{c}0.82 \\
(4.09) \\
(2.80)\end{array}$ & $\begin{array}{c}0.10 \\
(0.48) \\
(0.97)\end{array}$ & $\begin{array}{c}-1.15 \\
(-5.51) \\
(-2.45)\end{array}$ \\
\hline $\begin{array}{l}\text { Sum of above returns } \\
\text { (position reversed in quarter } t+4 \text { ) }\end{array}$ & 1.92 & 2.74 & 2.84 & 3.99 \\
\hline $\begin{array}{l}\text { Ratio of sum of three-day abnormal } \\
\text { returns through } t+k \text { to } C A R \\
\text { since quarter } t \text { announcement } \\
\text { (with reversal of long and short } \\
\text { positions in quarter } t+4 \text { ) }\end{array}$ & 0.24 & 0.28 & 0.27 & 0.35 \\
\hline \multicolumn{5}{|c|}{ Medium firms (23.541 to 30.904 observations) } \\
\hline $\begin{array}{l}\text { Abnormal return three days }[-2,0] \\
\text { around announcement. long (short) } \\
\text { in quarter isUE decile } 10(1) \\
t \text {-statistic } \\
\text { Alternative } t \text {-test }\end{array}$ & $\begin{array}{r}1.46 \\
(10.43) \\
(4.86)\end{array}$ & $\begin{array}{c}0.98 \\
(7.01) \\
(4.26)\end{array}$ & $\begin{array}{c}0.21 \\
(1.46) \\
(1.83)\end{array}$ & $\begin{array}{c}-0.44 \\
(-3.05) \\
(-1.62)\end{array}$ \\
\hline $\begin{array}{l}\text { Sum of above returns } \\
\text { (position reversed in quarter } t+4 \text { ) }\end{array}$ & 1.46 & 2.44 & 2.65 & 3.09 \\
\hline $\begin{array}{l}\text { Ratio of sum of three-day abnormal } \\
\text { returns through } t+k \text { to } C A R \\
\text { since quarter } t \text { announcement } \\
\text { (with reversal of long and short } \\
\text { positions in quarter } t+4 \text { ) }\end{array}$ & 0.22 & 0.27 & 0.27 & 0.31 \\
\hline \multicolumn{5}{|c|}{ Large firms (27,342 to 29,088 ohservations) } \\
\hline $\begin{array}{l}\text { Abnormal return three days }[-2,0] \\
\text { around announcement, long (short) } \\
\text { in quarter t SUE decile } 10(1) \\
\text { t-statistic } \\
\text { Alternative } t \text {-test }\end{array}$ & $\begin{array}{c}0.84 \\
(8.84) \\
(6.76)\end{array}$ & $\begin{array}{c}0.48 \\
(5.10) \\
(3.87)\end{array}$ & $\begin{array}{r}0.04 \\
(0.40) \\
(-0.30)\end{array}$ & $\begin{array}{c}-0.31 \\
(-3.24) \\
(-1.74)\end{array}$ \\
\hline $\begin{array}{l}\text { Sum of above returns } \\
\text { (position reversed in quarter } t+4 \text { ) }\end{array}$ & 0.84 & 1.32 & 1.36 & 1.67 \\
\hline $\begin{array}{l}\text { Ratio of sum of three-day abnormal } \\
\text { returns through } t+k \text { to } C A R \\
\text { since quarter } t \text { announcement } \\
\text { (with reversal of long and short } \\
\text { positions in quarter } t+4 \text { ) }\end{array}$ & 0.26 & 0.31 & 0.32 & 0.34 \\
\hline
\end{tabular}

Abnormal returns are the sum of daily returns for individual firms in the portfolio. less returns for NYSE-AMEX firms of the same size decile, based on January 1 market values of equity. Small, medium, and large firms are in size deciles 1 to 4,5 to 7 , and 8 to 10 , respectively. $C A R$ is the sum of abnormal returns over all days since the announcement for quarter $t$.

SUE represents the forecast error from a seasonal random-walk (with trend) earningsexpectation model, scaled by its estimation-period standard deviation. SUE decile portfolios are based on ranking of SUEs within the calendar quarter of the announcement of quarter , earnings.

bitternative $t$-test is conducted by calculating mean abnormal return for each of 13 years, and dividing by the time-series standard error of that mean. 


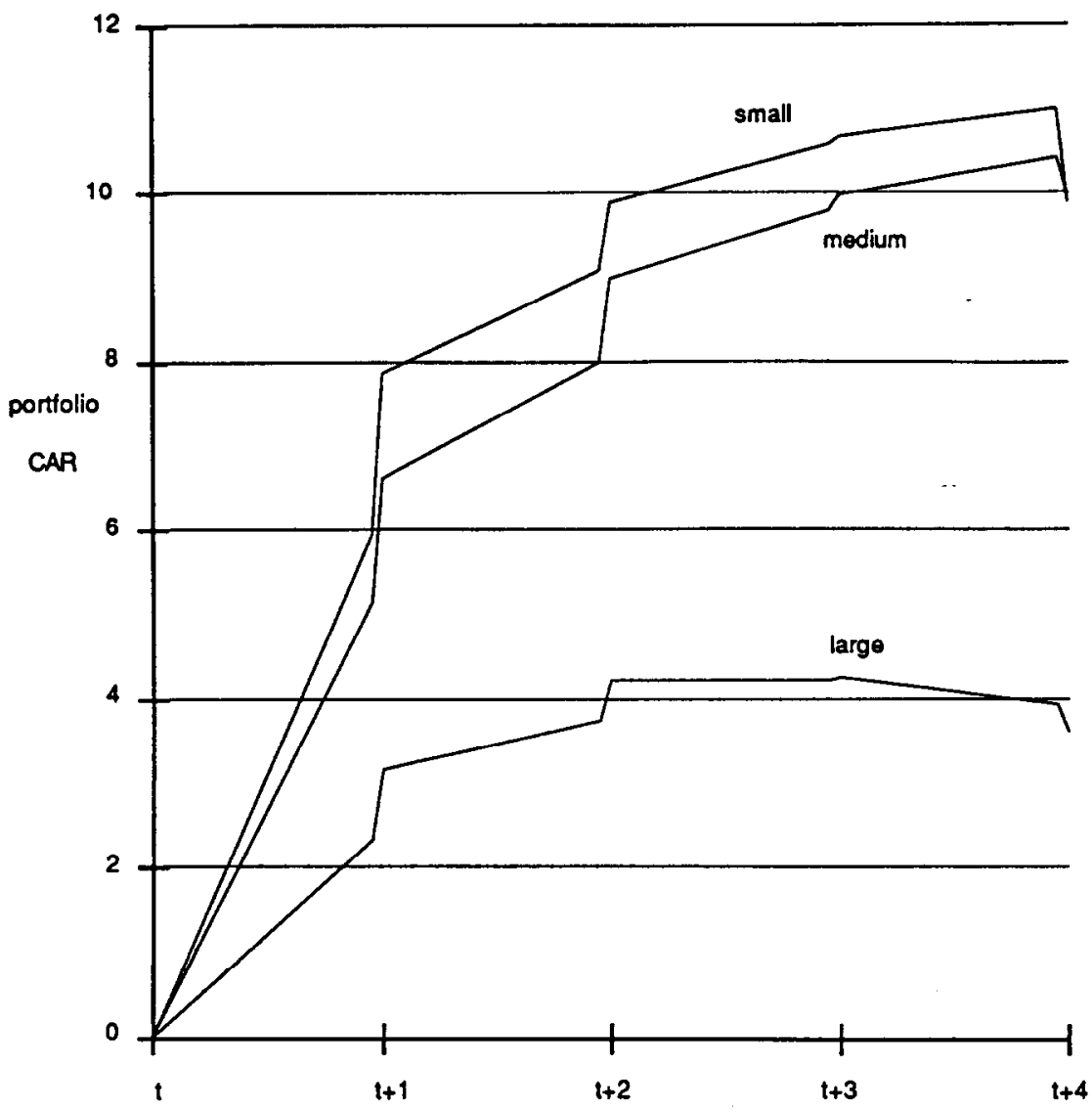

Announcement date of subsequent quarter, relative to announcement of quarter $t$

Fig. 1. Percentage cumulative abnormal returns for $S U E$ portfolios: Returns aligned by subsequent earnings announcements.

Portfolio $C A R$ is the percentage cumulative abnormal return over holding periods beginning after the earnings-announcement day for quarter $t$, for a portfolio invested long (short) in the highest (lowest) decile of standardized unexpected earnings (SUE) at quarter $t$. SUE represents forecast error from the seasonal random-walk (with trend) earnings-expectation model scaled by its estimation-period standard deviation. Abnormal returns are the differences between daily returns for individual firms in an SUE decile portfolio and returns for NYSE-AMEX firms of the same size decile, based on January 1 market values of equity. Small, medium, and large firms are in size deciles 1 to 4,5 to 7 , and 8 to 10 , respectively. Holding periods are obtained by splitting the period between adjacent earnings-announcement dates into a three-day preannouncement window (day -2 to day 0 ) and an inter-announcement window. While the actual inter-announcement windows vary in length, the mean value of 60 days is used to illustrate the differential price responses occurring in the two windows. 
the quarters, with the following exception. When either the first or second subsequent announcements pertain to the first quarter of the fiscal year, the three-day abnormal returns are only about half as large as reported in table 2. Although this result may be partially due to the lower-than-average first-order autocorrelations between fourth-quarter and subsequent firstquarter $S U E$ s, we are otherwise unable to explain this feature of the data.

\subsection{Regression tests of Hypothesis 2}

We now turn to tests of Hypothesis 2. These tests can be used to assess the economic importance of abnormal returns that are predicted using several prior earnings signals simultaneously. However, the tests require direct reliance on a specific model of earnings (the Brown-Rozeff model). Whether such reliance strengthens or weakens our tests depends on the validity of that model as a description of the actual univariate process of earnings.

Based on eqs. (6) and (7), we estimate regression models of the following form:

$$
\begin{aligned}
& A R_{j t}=b_{0}+b_{1}\left(Q_{j, t-1}-Q_{j, t-5}\right)+b_{4} e_{j, t-4}+u_{j t}, \\
& A R_{j t}=b_{0}+b_{1} e_{j, t-1}+b_{2} e_{j, t-2}+b_{3} e_{j, t-3}+b_{4} e_{j, t-4}+v_{j t},
\end{aligned}
$$

where $e_{j, t-k}$ is an estimate of the earnings shock $\varepsilon_{j, t-k}$ from eqs. (6) and (7) as discussed below, $u_{j t}$ and $v_{j t}$ are residual errors, and other variables are as previously defined.

The earnings shocks called for on the right-hand side of eqs. (8) and (9) are the forecast errors from a Brown-Rozeff model. However, in time series as short as that used here, the iterative techniques necessary to estimate the Brown-Rozeff model are often unreliable. To deal with this problem, we produced two sets of estimates of (8) and (9). One is based on a subset (36 percent) of the sample for which 36 historical observations are available to estimate the Brown-Rozeff earnings forecasts; forecast errors for this sample are available only beginning in 1980 . The second approach uses the full sample, extending from 1974 through 1986, but substitutes forecast errors from an alternative model developed by Foster (1977). ${ }^{9}$ Such errors are highly correlated with Brown-Rozeff forecast errors, even though the Foster model differs by excluding the fourth-order moving-average term. ${ }^{10}$ While

\footnotetext{
${ }^{9}$ The Foster model was estimated from the most recent 36 quarters of earnings data (after seasonal differencing), where available. Where fewer than 16 quarterly observations were available, we relied on a seasonal random walk to generate earnings expectations. This was necessary in about 6 percent of the cases.

${ }^{10}$ The correlation between the two forecast errors is 0.86 , when each is converted to a winsorized $S U E$ as was done previously with the seasonal differences; the correlation is 0.80 , when each is converted to SUE deciles.
} 
the substitution of Foster forecast errors weakens our tests by introducing some measurement error in the regressors, the impact should be small. ${ }^{11}$ In fact, for the subsample where both Brown-Rozeff and Foster forecast errors are available, the results are essentially the same; those results are, in turn, similar to those based on the full sample and Foster model forecasts errors.

Given that the alternative approaches yield similar results, we choose to report only one in detail. The approach selected is that based on the full sample (using the Foster model), bccause the results of that approach are readily comparable to those in the previous tables. Moreover, by emphasizing that the predicted results hold when Foster model forecast errors are used, we can remove any doubt that the implied abnormal returns could only have been obtained through application of the computer-intensive statistical estimation required by the Brown-Rozeff model. The Foster model, in contrast, could easily have been estimated throughout our sample period, using a simple regression.

Another measurement issue concerns scaling of the regressors. Both the seasonal difference $Q_{t-1}-Q_{t-5}$ and the earnings shocks $e_{t-1}$ through $e_{t-4}$ are scaled by their historical standard deviations (using up to 36 observations, where available), just as the SUEs were in the previous section. [Thus, the regressors could themselves be viewed as SUEs based on forecasts from a seasonal random walk (for $Q_{t-1}-Q_{t-5}$ ) and a Foster model (for $e_{t-1}$ through $\left.e_{t-4}\right)$.] The resulting scaled variables are then placed in deciles within quarters (to guard against the potential for difficulties with outliers) and the decile rankings ( 1 to 10 ) are reduced by one and then divided by nine so as to range between 0 and 1 .

Given the way we have constructed the regressions, the coefficients can be interpreted as abnormal returns on portfolios with certain useful properties. [See Fama and MacBeth (1973) and Bernard (1984) for similar interpretations.] First, denoting the dependent variable as $R$ and the matrix of regressors as $X$, note that the ordinary-least-squares (OLS) regression coefficients [written as $\left(X^{\prime} X\right)^{-1} X^{\prime} R$ ] represent abnormal returns on portfolios, where the portfolio weights are given by the rows of the matrix $\left(X^{\prime} X\right)^{-1} X^{\prime}$. Second, note that since the regression includes an intercept, the portfolio weights for the slope coefficients must sum to zero, and thus the slope coefficients can be viewed as abnormal returns to zero-investment portfolios. Third, to help interpret the economic meaning of the coefficient, note that a coefficient from a regression of abnormal returns can always be interpreted

\footnotetext{
${ }^{11}$ If the Brown-Rozeff and Foster model parameters could be estimated precisely, then movement from the former to the latter to estimate eq. (8) should introduce a bias toward zero in $b_{1}$ that is trivial and in $b_{4}$ that is on the order of 6 percent. (Details are available upon request.) For the subsample where both Brown-Rozeff and Foster forecast errors are available, the coefficient estimates based on the Foster model are indeed closer to zero, in the amount of 1 percent and 2 percent, respectively.
} 
as the abnormal return on a portfolio with a value of 1 for the associated regressor, and a value of 0 for the remaining regressors. Thus, the amount $b_{1}-b_{4}$ in eq. (8) represents the abnormal return on a zero-investment portfolio with a value of 1 for $Q_{t-1}-Q_{t-5}$ and -1 for $e_{t-4}$; the amount $b_{1}+b_{2}+b_{3}-b_{4}$ in eq. (9) represents the abnormal return on a zero-investment portfolio with value of 1 for $e_{t-1}, e_{t-2}$, and $e_{t-3}$ and -1 for $e_{t-1}$. (Of course, regressors for individual observations range from 0 to 1 , spanning the ten deciles of the distribution, but the observations arc weighted so that these statements hold for the portfolio.)

The above interpretations imply that, given how the regressors are scaled [with a value of $1(0)$ representing the highest (lowest) decile of a regressor distribution], the portfolio underlying $b_{1}-b_{4}$ in eq. (8) is comparable to a zero-investment portfolio with long (short) positions in firms within the highest (lowest) decile of $Q_{t-1}-Q_{t-5}$ and short (long) positions in firms within the highest (lowest) decile of $e_{t-4}$. Specifically, the two portfolios are comparable in the sense that both have values of 1 for $Q_{t-1}-Q_{t-5}$ and -1 for $e_{t-4}{ }^{12}$ Similarly, the portfolio underlying $b_{1}+b_{2}+b_{3}-b_{4}$ in (9) is comparable to a zero-investment portfolio with long (short) positions in firms within the highest (lowest) deciles of $e_{t-1}, e_{t-2}$, and $e_{t-3}$ and short (long) positions in firms within the highest (lowest) decile of $e_{t-4}$.

The essential point is that the linear combination of coefficients in regression (8) or (9) can be interpreted as abnormal returns on zero-investments portfolios that, unlike the portfolios in table 2 and prior research, are based on information about multiple earnings signals. Nevertheless, the portfolios implicit in the regression are scaled so as to permit comparisons with portfolios based on single earnings signals. In addition, the weights underlying them are determinable on the basis of information (the regressors) available prior to the beginning of the return interval.

Estimates of eqs. (8) and (9) are presented in table 5, panel A. The primary estimates based on three-day return intervals appear at the top of that panel. The abnormal returns implied by using the combination of prior period earnings signals [that is, $b_{1}-b_{4}$ for eq. (8) and $b_{1}+b_{2}+b_{3}-b_{4}$ for eq. (9)] appear in the rightmost column of panel $A$.

Coefficient estimates for both eqs. (8) and (9) at the top of panel $A$ all have the predicted signs $\left(b_{1}, b_{2}\right.$, and $b_{3}$ are all positive and $b_{4}$ is negative) and are always statistically significant. The relative magnitudes of the coefficients are also in accord with our expectations; that is, $b_{1}>b_{2}>b_{3}>0>b_{4}$. The adjusted $R^{2}$ is low in regressions (8) and (9) - less than 1 percent - indicating that only a small fraction of the variance in stock returns is predictable

\footnotetext{
${ }^{12}$ The portfolio underlying $b_{1}-b_{4}$ differs from the other portfolio in that, under the assumptions of OLS, the former is minimum variance. However, since the assumptions of OLS are unlikely to hold perfectly, the portfolio will not literally be minimum variance, thus weakening our tests.
} 
Table 5

Regression tests of relation between market reactions to quarterly earnings announcements and earnings information.

Panel A: Predicting market reaction using lagged earnings information ${ }^{a}$

(8) $A K_{j t}=b_{0}+b_{1}\left(Q_{j, t-1}-Q_{j, t-5}\right)+b_{4} e_{j, t-4}+u_{j t}$

(9) $A R_{j t}=b_{0}+b_{1} e_{j, t-1}+b_{2} e_{j, t-2}+b_{3} e_{j, t-3}+b_{4} e_{j, t-4}+c_{j t}$

\begin{tabular}{|c|c|c|c|c|c|c|c|}
\hline $\begin{array}{l}\text { Regression } \\
\text { model }\end{array}$ & $\begin{array}{l}\text { Holding period for } \\
\text { abnormal returns }\end{array}$ & $\begin{array}{c}b_{1} \\
(t-\text { statis }\end{array}$ & $\begin{array}{l}b_{2} \\
\text { stic and }\end{array}$ & $\begin{array}{l}b_{3} \\
\text { alternati }\end{array}$ & $\begin{array}{c}b_{4} \\
\text { ive } t \text {-test) }\end{array}$ & $\begin{array}{l}\text { Adj. } \\
R^{2}\end{array}$ & $\begin{array}{l}\text { Implied portfolio } \\
\text { abnormal return }\end{array}$ \\
\hline $\begin{array}{l}\text { Equation } 8 \\
(N=75,653)\end{array}$ & $\begin{array}{l}\text { Three-day }[-2,0] \\
\text { announcement } \\
\text { period for quarter } t\end{array}$ & $\begin{array}{c}1.30 \\
(20.59) \\
(12.22)\end{array}$ & & & $\begin{array}{c}-0.84 \\
(-13.29) \\
(-6.06)\end{array}$ & $0.7 \%$ & $2.14 C_{C}^{\circ}$ \\
\hline $\begin{array}{l}\text { Equation } 9 \\
(N=75,045)\end{array}$ & $\begin{array}{l}\text { Three-day }[-2,0] \\
\text { announcement } \\
\text { period for quarter }\end{array}$ & $\begin{array}{r}0.98 \\
(15.66) \\
(9.14)\end{array}$ & $\begin{array}{c}0.62 \\
(9.89) \\
(14.43)\end{array}$ & $\begin{array}{l}0.28 \\
(4.44) \\
(2.83)\end{array}$ & $\begin{array}{c}-0.71 \\
(-11.41) \\
(-9.04)\end{array}$ & $0.7 \%$ & $2.59 c^{\circ}$ \\
\hline $\begin{array}{l}\text { Equation } 8 \\
(N=75,443)\end{array}$ & $\begin{array}{l}\text { From day after prior } \\
\text { announcement, } \\
\text { to quarter } t \\
\text { announcement } \\
\text { (avg. } 63 \text { days) }\end{array}$ & $\begin{array}{r}6.24 \\
(34.40) \\
(9.41)\end{array}$ & & & $\begin{array}{r}-2.44 \\
(-13.41) \\
(-9.64)\end{array}$ & $1.6 \%$ & $8.68 \%$ \\
\hline $\begin{array}{l}\text { Equation } 9 \\
(N=74,837)\end{array}$ & $\begin{array}{l}\text { From day after prior } \\
\text { announcement, } \\
\text { to quarter } t \\
\text { announcement } \\
\text { (avg. } 63 \text { days) }\end{array}$ & $\begin{array}{r}5.38 \\
(29.99) \\
(6.56)\end{array}$ & $\begin{array}{l}1.46 \\
(8.10) \\
(3.22)\end{array}$ & $\begin{array}{l}0.53 \\
(2.94) \\
(0.18)\end{array}$ & $\begin{array}{l}-1.56 \\
(-8.68) \\
(-5.32)\end{array}$ & $1.4 \%$ & $8.93 \%$ \\
\hline
\end{tabular}

Panel B: Contemporaneous association: market reaction and earnings information ${ }^{\text {a }}$

$$
\begin{aligned}
& \text { (A) } A R_{j t}=b_{0}+b_{1} e_{j t}+w_{j t} \\
& \text { (B) } A R_{j t}=b_{0}+b_{1}\left(Q_{j, t}-Q_{j, t-4}\right)+z_{j t}
\end{aligned}
$$

\begin{tabular}{|c|c|c|c|c|}
\hline $\begin{array}{l}\text { Regression } \\
\text { model }\end{array}$ & $\begin{array}{l}\text { Holding period for } \\
\text { abnormal returns }\end{array}$ & $\begin{array}{c}\text { Regression coefficient, } b_{1} \\
\text { ( } t \text {-statistic and alternative } t \text {-test) }\end{array}$ & Adj. & $\begin{array}{l}\text { Implied portfolio } \\
\text { abnormal return }\end{array}$ \\
\hline $\begin{array}{l}\text { Equation A } \\
(N=82,734)\end{array}$ & $\begin{array}{l}\text { Three-day }[-2,0] \\
\text { announcement } \\
\text { period for quarter } t\end{array}$ & $\begin{array}{c}4.18 \\
(71.61) \\
(26.34)\end{array}$ & $5.8 \%$ & $4.18 \%$ \\
\hline $\begin{array}{l}\text { Equation B } \\
(N=85,493)\end{array}$ & $\begin{array}{l}\text { Three-day }[-2,0] \\
\text { announcement } \\
\text { period for quarter } t\end{array}$ & $\begin{array}{c}4.43 \\
(76.27) \\
(19.27)\end{array}$ & $6.4 \%$ & $4.43 \%$ \\
\hline
\end{tabular}

\footnotetext{
${ }^{a}$ Abnormal returns, $A R_{j t}$, represent the sum over the indicated holding periods of the differences between daily returns for firm $j$ and returns for NYSE-AMEX firms of the same size decile, based on Jaruary 1 market values of equity. $Q_{t}-Q_{t-4}$ is seasonally differenced quarterly earnings and $e_{t}$ is the forecast error from the Foster (1977) first-order autoregressive earnings-expectation model (in seasonal differences); both are scaled by their historical standard deviation. All regressors are assigned to deciles, based on the current quarter distribution, and then scaled so that they range from 0 (for the lowest decile) to 1 (for the highest decile). Implied portfolio abnormal returns are equal to $\left(b_{1}-b_{4}\right)$ and $\left(b_{1}+b_{2}+b_{3}-b_{4}\right)$ in panel $\mathrm{A}$, and $b_{1}$ in panel B. Alternative $t$-test is conducted by estimating regressions for each of 13 years, and comparing each coefficient's mean to its time-series standard error.
} 
based on previously announced earnings information. However, we will show later (table 7) that the remaining variance is largely diversifiable within annual cross-sections, yielding abnormal returns with the predicted signs consistently from year to year.

Turning to the implied portfolio abnormal return on the right-hand side of panel $\mathrm{A}$, we see that a combination of prior period earnings signals improves our ability to predict future reactions to earnings announcements. Note that the implied abnormal returns are larger than any of the coefficients on individual regressors, and larger than any of the portfolio returns in table 2 , each of which is based on a single earnings signal. Results based on eqs. (8) and (9) imply that, on average, historical earnings information could have been used to construct a portfolio with an abnormal return of 2.1 percent and 2.6 percent, respectively, over the three-day announcement-period interval.

Table 5 also provides two ways to assess the economic importance of the predictions. The first moves away from emphasis on three-day intervals surrounding subsequent earnings announcements, and focuses instead on portfolios formed immediately after the current announcement. ${ }^{13}$ The portfolios are held until the next announcement (a period of approximately 63 trading days, on average). If an investor believes that post-announcement drift represents a delayed price response, there would be no good reason to wait until just prior to subsequent announcements to take a position. Moreover, the timing of the subsequent announcement cannot be predicted perfectly in advance. Thus, transacting just after the current announcement may represent a better depiction of the strategy an investor might pursue. However, the movement to longer windows increases the concerns about measurement error in abnormal returns.

Regressions using the longer return intervals are presented at the bottom of table 5, panel A. The implied abnormal return over one quarter for the portfolio constructed using information about two earnings signals $-\left(Q_{t-1}-\right.$ $Q_{t-5}$ ) and $e_{t-4}-$ is 8.7 percent. When signals about each of the prior four earnings announcements are used $-e_{t-1}, e_{t-2}, e_{t-3}$, and $e_{t-4}-$ the implied abnormal return is 8.9 percent. The magnitudes of these abnormal returns, corresponding to implied annualized abnormal returns on the order of 35 percent, are significant in economic as well as statistical terms.

There is a second approach to evaluating the economic importance of the effects documented here, that has more direct implications for methodology. We compare the implied three-day abnormal return from panel $A$, which is predicted solely on the basis of historical information, to the three-day abnormal return that could be generated if earnings were known with

\footnotetext{
${ }^{13}$ The values of two regressors, the decile assignments of $\left(Q_{t-1}-Q_{t-5}\right)$ and $e_{t-1}$, depend on a firm's earnings relative to other firms, and thus cannot be calculated until all firms have announced earnings. However, as explained in footnote 7 , the potential hindsight bias this introduces appears trivial in this sample.
} 
certainty three days before the announcement. The latter abnormal return is presented in panel $B$, where we regress abnormal returns around the announcement of earnings for quarter $t$ against measures of unexpected earnings (either $Q_{t}-Q_{t-4}$ or $e_{t}$ ) for that same quarter. (Consistent with our approach in panel $A$, the regressor ranges from 0 to 1 , depending on the decile to which estimated unexpected earnings belongs.) The regression indicates that the zero-investment portfolio comparable to one with a long (short) position in stocks in the highest (lowest) decile of current unexpected earnings generates an abnormal return of 4.2 or 4.4 percent, depending on how unexpected earnings is defined. These amounts can then be compared to the three-day abnormal returns of 2.1 or 2.6 percent in panel $\mathrm{A}$.

The above comparison indicates that, using only historical, publicly available earnings data, we are able to generate an abnormal return about half as large as that based on perfect foresight of earnings. Thus, the abnormal return that can be predicted in advance is approximately half as large as the stock-price reaction to what is labeled 'unexpected earnings' in many accounting research studies. This result calls into question the reliability of studies that rely heavily on the assumption that prices reffect all publicly available earnings information quickly. Of some consolation, however, is the observation that the fraction of variance in announcement-period abnormal returns explained by prior-period earnings information is small ( 0.7 percent), in both absolute terms and relative to the $R$-squared based on current earnings, which is 5.8 percent.

Eq. (8) is re-estimated within firm-size categories in table 6, panel A. Using the combination of indicators from prior earnings numbers, the mean threeday abnormal return on the implied zero-investment portfolio is 3.4 percent, 2.2 percent, and 1.2 percent for small, medium, and large firms, respectively. The regression results in panel B indicate that if one could forecast the SUE perfectly, the resulting mean three-day abnormal return would be 6.8 percent, 3.7 percent, and 2.3 percent, for small, medium, and large firms, respectively. In each case, the return based solely on historical information is about half as large as that based on perfect foresight.

A final note concerns the potential for further improvement in the ability to predict abnormal returns around future earnings announcements by considering cross-sectional differences in the parameters of individual firms' time-series processes. We examined this issue in two ways. First, in regressions not reported here, we used historical estimates of $\phi$ and $\theta$ in eq. (8), as called for by eq. (6). Predictive ability was not improved; the implied abnormal returns were similar to those reported in table 5. Second, we stratified the sample into four quartiles, first based on historical estimates of $\phi$ and then (separately) based on historical estimates of $\theta$, and repeated the portfolio tests of table 2 within each group. As expected, the abnormal return at the announcement of quarter $t+1$ earnings was most (least) positive for 
Table 6

Regression tests of relation between market reactions to quarterly earnings announcements and earnings information; results by firm-size group.

Panel A: Predicting market reaction using lagged earnings information ${ }^{3}$

\begin{tabular}{lcccc} 
Firm-size & $(8) \quad \begin{array}{c}A R_{j t}=b_{0}+b_{1}\left(Q_{j, t-1}-Q_{j, t-5}\right)+b_{+} e_{j, t-4}+u_{j t} \\
\text { category }\end{array}$ & $\begin{array}{l}b_{1} \\
(t \text {-statistic and alternative } t \text {-test })\end{array}$ & $\begin{array}{c}\text { Adj. } \\
R^{2}\end{array}$ & $\begin{array}{c}\text { Implied portfolio } \\
\text { abnormal return }\end{array}$ \\
\hline $\begin{array}{lccc}\text { Small firms } \\
(N=26,841)\end{array}$ & 1.98 & -1.37 & $0.8 \%$ & $3.35 \%$ \\
& $(13.37)$ & $(-9.32)$ & & \\
Medium firms & $(9.88)$ & $(-7.30)$ & & $2.20 \sigma_{c}$ \\
$(N=22,204)$ & 1.49 & -0.71 & $1.0 \%$ & \\
& $(14.76)$ & $(-7.00)$ & & $1.23 \%_{c}$ \\
Large firms & $(5.40)$ & $(-4.66)$ & & \\
$(N=26,438)$ & 0.80 & -0.43 & $0.6 \%$ & \\
& $(11.69)$ & $(-6.52)$ & & \\
\hline
\end{tabular}

Panel B: Contemporaneous association: market reaction and earnings information ${ }^{\mathrm{a}}$

$$
A R_{j t}=b_{0}+b_{1} e_{j t}+w_{j t}
$$

Firm-size

Regression coefficient, $b_{1}$ category ( $t$-statistic and alternative $t$-test)

Adj. $R^{2}$

Implied portfolio abnormal return

\begin{tabular}{lccc}
\hline Small firms & 6.77 & $7.9 \%$ & $6.77 \%$ \\
$(N=29,694)$ & $(50.58)$ & & \\
Medium firms & $(19.97)$ & $6.3 \%$ & $3.74 \%$ \\
$(N=24,163)$ & 3.74 & & \\
& $(40.32)$ & $4.5 \%$ & $2.28 \%$ \\
Large firms & $(24.57)$ & & \\
$(N=28,482)$ & 2.28 & &
\end{tabular}

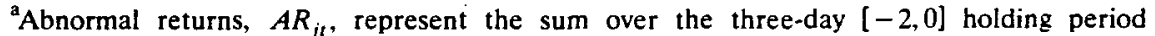
(relative to the announcement date for quarter $t$ ) of the differences between daily returns for firm $j$ and returns for NYSE-AMEX firms of the same size decile, based on January 1 market values of equity. Small, medium, and large firms are in size deciles 1 to 4,5 to 7 , and 8 to 10 , respectively. $Q_{t}-Q_{t-4}$ is seasonally differenced quarterly earnings and $e_{t}$ is the forecast error from the Foster (1977) first-order autoregressive earnings-expectation model (in seasonal differences); both are scaled by their historical standard deviation. All regressors are assigned to deciles, based on the current-quarter distribution, and then scaled so that they range from 0 (for the lowest decile) to $\mathbb{I}$ (for the highest decile). Implied portfolio abnormal returns are equal to $\left(b_{1}-b_{4}\right)$ in panel $\mathrm{A}$ and $b_{1}$ in panel $\mathrm{B}$. Alternative $t$-test is conducted by estimating regressions for each of 13 years, and comparing each coefficient's mean to its time-series standard error.
} 
the portfolio with the largest (smallest) historical value for $\phi$ (1.54 percent versus 1.21 percent), and the abnormal return at quarter $t+4$ was most (least) negative for the portfolio with the largest (smallest) historical value for $\theta$ ( -1.09 percent versus -0.74 percent). However, the differences were not statistically significant. One possible explanation is that cross-sectional differences in time-series parameters are too small to provide much predictive power. (Recall the similarity in time-series behavior across industries in table 1.) Another possibility is that while cross-sectional differences exist, they are unstable or estimated with considerable error. Much of the time-series literature [e.g., Albrecht, Lookabill, and McKeown (1977), Foster (1977), Watts and Leftwich (1977)] is consistent with such cross-sectional differences not being predictable out of sample.

\section{Alternative explanations and additional evidence}

It is difficult to understand how stock prices could fail to reflect the implications of current earnings for future earnings in such a systematic way. The evidence naturally raises several questions, which we discuss below.

(1) Can this evidence be explained in terms of rational investors' desire to await 'confirmation' that a previous earnings change is not transitory?

An immediate problem with this explanation is that, at best, it fits only the patterns observed around the announcements of earnings for quarters $t+1$, $t+2$, and $t+3$; the reactions for quarter $t+4$ are consistent with investors treating previous earnings as if they were more permanent than they turned out to be.

There is a more fundamental problem with this explanation, however. No matter how much uncertainty surrounds the implications of earnings already announced for quarter $t$, prices in an efficient market would immediately reflect an unbiased expectation of future earnings, and future abnormal returns would be uncorrelated with past earnings changes. Even if increased uncertainty caused by extreme earnings changes is relevant for pricing, it could not explain the evidence. While it is true in that case that a postannouncement drift (actually, a risk premium) would be observed, it would be positice for both extreme-bad-news and extreme-good-news firms. [See Brown, Harlow, and Tinic (1988).] Both the existing literature on post-announcement drift and this study (see table 2) document a negative drift for bad-news firms.

(2) Does the etidence reflect autocorrelations in earnings that were observable ex post, but not predictable ex ante?

Two pieces of evidence contradict this explanation. First, the autocorrelation patterns we observed in our sample period were also observed by Foster for 
Table 7

Consistency (over time) of relation between market reactions to future earnings announcements and current-quarter earnings information.

\begin{tabular}{|c|c|c|c|c|}
\hline \multirow[b]{2}{*}{ Year } & \multicolumn{4}{|c|}{$\begin{array}{l}\text { Mean abnormal return during three-day }[-2,0] \text { window around } \\
\text { earnings announcement for quarter } t+k \text {, for portfolio including long } \\
\text { (short) position in firms in highest (lowest) decile of } S U E \text { in quarter } t^{\mathrm{a}} \\
\text { (predicted sign of abnormal return in parentheses) }\end{array}$} \\
\hline & $\begin{array}{c}t+1 \\
(+)\end{array}$ & $\begin{array}{c}t+2 \\
(+)\end{array}$ & $\begin{array}{r}t+3 \\
(+)\end{array}$ & $\begin{array}{c}t+4 \\
(-)\end{array}$ \\
\hline 1974 & $3.74^{\mathrm{c}}$ & $3.05^{\mathrm{c}}$ & 0.89 & $N A^{b}$ \\
\hline 1975 & $2.28^{\mathrm{c}}$ & $0.80^{c}$ & -0.43 & $-1.32^{c}$ \\
\hline 1976 & $1.30^{\mathrm{c}}$ & 0.41 & -0.15 & $-0.98^{c}$ \\
\hline 1977 & $1.69^{c}$ & $0.87^{c}$ & -0.01 & -0.41 \\
\hline 1978 & $1.06^{\mathrm{c}}$ & $0.78^{c}$ & $0.69^{c}$ & -0.15 \\
\hline 1979 & $1.08^{\mathrm{c}}$ & $0.76^{\mathrm{c}}$ & -0.10 & -0.39 \\
\hline 1980 & $1.48^{\mathrm{c}}$ & $0.87^{\mathrm{c}}$ & 0.21 & $-0.98^{c}$ \\
\hline 1981 & $1.10^{\mathrm{c}}$ & $0.78^{\mathrm{c}}$ & 0.20 & $-0.57^{\mathrm{c}}$ \\
\hline 1982 & $1.08^{c}$ & 0.26 & -0.19 & $-1.05^{\mathrm{c}}$ \\
\hline 1983 & $1.11^{\mathrm{c}}$ & $0.73^{c}$ & 0.12 & $-0.75^{\mathrm{c}}$ \\
\hline 1984 & $0.70^{c}$ & $0.50^{\mathrm{c}}$ & 0.27 & -0.06 \\
\hline 1985 & $1.12^{\mathrm{c}}$ & 0.19 & -0.70 & $-0.91^{c}$ \\
\hline 1986 & $0.84^{\mathrm{c}}$ & $0.81^{\mathfrak{c}}$ & 0.54 & -0.19 \\
\hline
\end{tabular}

${ }^{\mathrm{a}} S U E$ represents forecast error from the seasonal random-walk (with trend) earnings-expectation model, scaled by its estimation-period standard deviation. Abnormal returns are the differences between daily returns for individual firms in the $S U E$ decile portfolio and returns for NYSE-AMEX firms of the same size decile, based on January 1 market values of equity.

${ }^{\mathrm{b}}$ Since SUEs are calculated beginning in the first quarter of 1974 , four-quarter-ahead predictions are not possible for any quarter in that year.

${ }^{c}$ Statistically significant at 0.05 level, one-tailed test.

1946-1974. In fact, the positive autocorrelations in earnings changes at lags 1,2 , and 3 are weaker during our sample period than in Foster's earlier period, making it difficult to argue that the market was justified in being surprised at the degree of autocorrelation in earnings observed in our sample. [Our own expectations were based largely on the evidence in Foster (1977), and the evidence in tables 2 through 5 was generated before we produced the autocorrelations reported in table 1.]

The second piece of evidence is presented in table 7. Although the market might err in its expectations about the degree of autocorrelation in earnings, it is difficult to explain how it could justifiably err in the same direction year after year. Table 7 shows that the mean three-day abnormal returns around the announcement for quarter $t+1$ and $t+2$ (for portfolios formed based on earnings of quarter $t$, as they were for table 2) is positive for 13 consecutive years. The mean abnormal return around the announcement of quarter $t+4$ earnings is negative for each of the 12 years for which we have data. (Results for quarter $t+3$ are weak, but that is not unexpected, given the weak third-order autocorrelation in seasonally differenced earnings.) Of 
course, the consistency in the results also makes it that much harder to understand how competitive market forces could fail to eliminate the anomaly.

Incidentally, there is a suggestion in table 7 that the predictable component of the reaction to earnings announcements is larger in the first two to four years of our sample period (that is, 1974, 1975, and perhaps 1976 and 1977) than in subsequent years. This may raise questions about whether the effect has for some reason dissipated over time. However, when we conduct similar tests for the years 1971-1973, the results are quite similar to those for years after $1977 .^{14}$

(3) Is the evidence explainable in terms of transactions costs?

One immediate response to this question is that, when the entire period from one earnings announcement to the next is considered, the abnormal returns appear to be in excess of transactions costs, perhaps even for small investors. (Recall the implied abnormal returns between the announcements for quarters $t$ and $t+1$ of about 9 percent for the combined long and short positions underlying the last two regressions in table 5, panel A; the more simple strategy of going long (short) in extreme-good-news (extreme-bad-news) firms yields an abnormal return over 180 days of 4.5 percent, 8.9 percent, and 9.9 percent for large, medium, and small firms [Bernard and Thomas (1989, table 1)]. Moreover, Freeman and Tse (1989, table 7) document that when SUEs are measured using analysts' forecasts, the indicated drift is even larger - by 50 percent - than when SUEs are based on the statistical forecasts used by Bernard and Thomas.

Even if the abnormal returns are within transactions costs for small investors, a transactions-cost argument can at best provide only a partial explanation. First, and most important, even if transactions costs cause 'sluggishness' in prices, it is hard to understand why the resulting 'mispricing' would last for months, or why it would be related to the historical time-series behavior of earnings. It is particularly difficult to reconcile 'price sluggishness' with the 'return reversal' we detect upon the announcement of earnings for quarter $t+4$. Second, any transactions-cost-based explanation raises questions about why information can't be impounded in prices by traders for whom transactions costs are low, or other traders for whom the transactions costs are irrelevant (because they have already committed to buy or sell for reasons unrelated to earnings information). Third, while transactions costs may prevent trades and therefore prevent the impounding of new information, they cannot explain why information is not completely impounded, given that trades have occurred.

\footnotetext{
${ }^{14}$ Since our earnings data begin only in 1970 , we have insufficient data to calculate the denominator of the SUE for years prior to 1974. Thus, for this supplemental analysis, we scaled unexpected earnings by the beginning-of-quarter stock-market value of equity. For the years for which both scale factors were available (1974-1986), the choice of scale factor does not alter the general nature of the results.
} 
(4) Could a research design flaw, such as a failure to control for risk. explain the evidence?

While these possibilities can never be completely dismissed, we believe the evidence is more difficult to explain as a research design flaw than any previous evidence on post-announcement drift. Consider, for example, what would be necessary to explain the results in terms of a failure to control for risk shifts. Firms announcing good (bad) news at quarter $t$ would need to experience a temporary upward (downward) shift in risk that occurs three months later, six months later, and nine months later, and then a downward (upward) shift in risk twelve months later. In addition to requiring risk changes in opposite directions for the same portfolios, this explanation also requires that the changes occur over short periods that coincide with an earnings-announcement date. Moreover, one would have to explain why the risk shifts are large, relative to those that generate 'normal' risk premia. Note that the three-day abnormal return around the announcement for quarter $t+1$ in table 2, panel A represents an annualized amount on the order of 200 percent (with no compounding).

Even if an explanation based on risk shifts could accommodate each of the above-mentioned features of the data, one important feature would remain to be explained. If the positive mean abnormal returns to zero-investment portfolios represent only a compensation for risk-bearing, then that risk should surface from time to time in the form of a loss. However, the consistent behavior of the abnormal returns through time (see table 7) indicates that the zero-investment strategy suggested by the anomaly would have earned positive abnormal returns for 13 consecutive years.

Potential bias related to imbalances in bids and asks. Even though risk shifts seem unlikely to explain the evidence, other research design flaws remain to be considered. Marais (1989), in discussing the post-announcement drift documented by Bernard and Thomas, notes that one 'cannot rule out consideration' of measurement errors in CRSP returns caused by an imbalance of bids and asks at the end of earnings-announcement days. Note that since CRSP prices are not 'true' prices, but may equal either the closing bid or closing ask, CRSP returns may be biased for any portfolio where there are more end-of-day transactions recorded at the bid than the ask, or vice versa [Keim (1989)]. Although such a bias could possibly play a role in our results, there is no compelling reason to expect it ex ante. It is not obvious why earnings for quarter $t$ would have any bearing on whether closing prices are recorded at the bid or the ask after announcements that occur three to twelve months later. Further, it is not obvious why the bias from the imbalance would be a function of quarter $t S U E \mathrm{~s}$, or why it would switch signs from quarter $t+3$ to quarter $t+4$. One possibility is that institutional arrangements might lead some investors to prefer to buy (sell) after a year-to-year earnings increase (decrease) in earnings, even though the in- 
crease (decrease) was predictable and already reflected in prices. If so, their actions could cause stocks with good (bad) earnings news for quarter $t$ to tend to close at the ask (bid) after the earnings announcement for quarter $t+1, t+2$, and $t+3$, and at the bid (ask) for quarter $t+4$. The resulting measurement error in CRSP returns would then give the appearance of abnormal returns in the directions we hypothesize.

To investigate this explanation, we conducted a test for bias due to imbalances in bid-ask spreads. If there is an imbalance between bids and asks on a given earnings announcement day, the bias should be reversed in subsequent days as the proportion of bids and asks returns to normal. Therefore, the positive (negative) estimated abnormal returns in the announcement period would be offset by negative (positive) estimated abnormal returns over the subsequent days. However, we find no compelling evidence of such a reversal in the two-day returns subsequent to the earningsannouncement day. Recall from table 2 that the abnormal returns for the three days prior to and including announcements for quarters $t+1, t+2$, $t+3$, and $t+4$ are 1.32 percent, 0.70 percent, 0.04 percent, and -0.66 percent for portfolios based on extreme $S U E$ deciles. The corresponding abnormal returns for the two days after the announcement are -0.04 percent, -0.07 percent, -0.03 percent, and 0.05 percent. The signs of these abnormal returns are all consistent with a reversal of a bid-ask bias, but the magnitudes are statistically insignificant and fall far short of the amounts necessary to offset the announcement period returns. (Upon detecting evidence at least weakly consistent with a partial reversal over the first two post-announcement days, we then examined the ten-day post-announcement period, but again there was little or no evidence of a reversal.)

Potential hindsight bias arising from restatements of Compustat data. Another possibility is that our results are biased by the use of earnings data that represent Compustat restatements, rather than the earnings information actually made available on the announcement day. Compustat restates prior quarter carnings when firms undergo major acquisitions, make accounting changes, or separately report income from discontinued operations. Evidence in at least two prior studies [Watts (1978) and Foster, Olsen, and Shevlin (1984)] suggests that these restatements are not responsible for inducing post-announcement drift. ${ }^{15}$ Furthermore, we can conceive of no reason why such restatements would induce a bias related to the autocorrelation structure of earnings.

\footnotetext{
${ }^{15}$ In his study of post-announcement drift, Watts (1978) used earnings data as originally reported. Foster, Olsen, and Shevlin (1984) collected earnings data as it was originally reported for a subsample of firms and detected post-announcement drift for that sample. [Foster, Olsen, and Shevlin (1984, p. 580) report that they hand-collected earnings-announcement dates. However, conversation with Olsen revealed that the earnings information itself was also hand-collected for this subsample.]
} 
Despite the indications that Compustat restatements are unlikely to explain our results, we conducted an additional test for this form of hindsight bias. Our approach was to identify the 275 sample firms for which Compustat's annual earnings amount (which is not restated) matched (within one thousand dollars) the sum of quarterly earnings per Compustat for each of the 13 years in the dataset. When Compustat restatements occur in the first three quarters of the year, prior-year quarterly numbers are affected, thus destroying the articulation between Compustat's quarterly and annual amounts. Thus, our subsample includes firms for which over a 13-year period there was either never a restatement or only restatements that occurred in the fourth quarter (affecting only the first three interim reports of the current year). Thus, this subsample includes firms for which restatements (1) were probably less frequent than for the sample as a whole and (2) should not have affected the reported fourth-quarter earnings. Therefore, if restatements of Compustat data explain our results, then within this subsample we would expect (1) a weakening of the results across all quarters and (2) no ability to predict reactions to future earnings announcements based on fourth-quarter earnings information. In contrast, however, whether we use earnings information from all quarters or the fourth quarter only, we obtain results that are similar to (and actually somewhat stronger than) those for the full sample.

(5) Do the three-day abnormal returns documented here represent the return on an implementable trading strategy, particularly since earnings-announcement dates cannot be predicted perfectly in advance?

The evidence based on three-day abnormal returns is not intended as a study of an implementable strategy; rather, it is intended to help us better understand a previously documented, more readily implementable trading strategy that involves holding stocks over much longer intervals beginning the day after an earnings announcement [see table 2, panel $B$, the bottom half of table 5, panel A, and Bernard and Thomas (1989, especially section 3.2.5)]. Nevertheless, since post-announcement drift is concentrated around subsequent carnings announcements and since the timing of those announcements is rather predictable [Chambers and Penman (1984)], an interesting question arises. How large an abnormal return per unit time could be generated by taking positions just prior to the expected dates of earnings announcements?

To examine the issue, we assume investors construct portfolios in the same way implicit in regression eq. (8), and that the positions are taken 15 trading days prior to the expected announcement date, where the expected date is the actual announcement date for the comparable quarter of the prior year. We hold the position until the day earnings are announced, or for 30 days, whichever occurs first. The actual holding period is, on average, 15 days. The implied abnormal return to this strategy is 4.2 percent. On an annualized basis (before compounding), this is equivalent to 67 percent. 


\section{Relation to other research}

Aside from Bernard and Thomas (1989) and Freeman and Tse (1989), the evidence presented here is most closely related to that of Wiggins (1990) and Mendenhall (forthcoming). Wiggins documents abnormal returns around subsequent earnings announcements that are consistent with those reported in our table 2; the most important distinction between this paper and Wiggins is that we develop the detailed relations between the signs and magnitudes of the abnormal returns and the autocorrelation structure of earnings. ${ }^{16}$

Mendenhall tests the validity of the Bernard and Thomas (1989) conjecture that market prices 'fail to reflect the full implications of current earnings for future earnings.' Mendenhall first documents that Value Line earnings forecasts are not efficient with respect to information in the latest earnings announcement - which is consistent with at least one set of market participants failing to respond completely to recent earnings information. Mendenhall then documents that reactions to earnings announcements can be partially predicted in advance, based on the most recent Value Line earnings-forecast revision. Thus, in forming earnings expectations, stock prices appear to ignore not only the full implications of prior earnings information, as documented here, but also previously announced analyst forecasts.

The evidence summarized here is also related to several other streams of research that are not focused directly on the issue of post-announcement drift.

Alternatice earnings forecasts as proxies for market expectations. Several studies have compared earnings-forecast errors from alternative sources (analysts, statistical models, etc.) in terms of their ability to explain contemporaneous stock returns. Surprisingly, Foster (1977) finds that forecast errors from a seasonal random-walk model yield marginally greater explanatory power than errors from more accurate statistical models. Bathke and Lorek (1984) and O'Brien (1988) provide evidence that is inconsistent with Foster's anomalous result, but $O^{\prime} B$ rien offers another anomaly that is at least as surprising. Specifically, she finds that forecast errors from the Foster model provide better explanations of contemporaneous stock returns than forecast errors of analysts who report to IBES, even though the analysts' forecasts are more accurate. [However, Brown, Griffin, Hagerman, and Zmijewski (1987) find that forecast errors based on Value Line are more highly associated with contemporaneous returns.]

The evidence presented here suggests that the 'anomalies' uncovered in prior research may in fact reflect predictable errors in the earnings expecta-

\footnotetext{
${ }^{16}$ Although the first draft of this paper predates the first draft of the Wiggins (1990) paper, the two papers were developed independently.
} 
tions underlying stock prices, as opposed to a research design flaw or some other explanation. If prices fail to reflect the implications of all publicly available information for future earnings, then it is possible that contemporaneous movements in stock prices are better explained by forecast errors based on an inferior forecasting source.

'Rationality' of the contemporaneous stock-price response to earnings. Kormendi and Lipe (1987) and Easton and Zmijewski (1989) find evidence consistent with stock prices reflecting cross-sectional differences in the timeseries behavior of earnings, in terms of differences in the response to current earnings. Freeman and Tse (1989) find evidence consistent with stock prices reflecting at least some of the implications of current earnings for future earnings. The evidence presented here suggests that, while stock prices may partially reflect such information, they evidently do not reflect all available information. In fact, given that post-announcement drift per unit time is not much smaller than pre-announcement drift [see Bernard and Thomas (1989, figs. 1 and 2)], the evidence suggests that the market's impounding of available information may be far from complete.

Other ecidence on market efficiency. Several recent studies offer evidence interpreted as inconsistent with semi-strong market efficiency. At least two of these [Hand (1990) and Ou and Penman (1989)] could be viewed as indications that stock prices reflect a naive earnings expectation. In that sense, the studies are consistent with the evidence presented here. However, Hand focuses on an unusual sample (firms that reported gains from debt-equity swaps), and thus it is not clear that the phenomenon underlying his results is linked with that studied here. Ou and Penman (1989, p. 327) conclude that their ability to predict future abnormal returns based on fundamental analysis is distinct from the phenomenon of post-announcement drift. Perhaps no single theme could explain each of these anomalies.

\section{Concluding remarks}

The evidence summarized here is consistent with the hypothesis that stock prices partially reflect a naive earnings expectation: that future earnings will be equal to earnings for the comparable quarter of the prior year. We considered a variety of alternative explanations for the evidence, including problems with risk adjustment and the impact of transactions costs, but were unable to support the viability of any of them.

In some ways, evidence like that presented here raises more questions than it answers. Why markets as competitive as the NYSE or AMEX would behave as if they are influenced by naive earnings expectations is difficult to understand. 
Another question concerns the economic importance of the effects documented here. In one sense, the degree of 'mispricing' that might be indicated by post-announcement drift is 'small' - less than 5 percent of price per position, even for cases of extreme earnings realizations [see Bernard and Thomas (1989) and the long-interval results in tables 2 and 4 of this paper]. However, in some other ways, the potential effect is large. First, previous studies [e.g., Bernard and Thomas (1989, table 1)] have found that what appears to be a delayed reaction to earnings is more than one-third as large as the anticipatory and contemporaneous reaction. Second, we find here that the three-day announcement-period returns on portfolios constructed with only prior-quarter earnings information are approximately half as large as the return to portfolios constructed using the contemporaneous earnings information. Such evidence may be cause for concern in interpreting the results of the many studies that assume that earnings information is fully impounded by the end of the earnings-announcement day. Moreover, if market prices fail to reflect fully the implications of information as freely available as earnings, how well do they reflect information that is not as well-publicized?

\section{References}

Albrecht. S., L. Lookabill, and J. McKeown, 1977, The time series properties of annual earnings. Journal of Accounting Research 15, 226-244.

Ball, R. and S.P. Kothari, 1990, Security returns around earnings announcements. Working paper (University of Rochester, Rochester, NY).

Ball, R., S.P. Kothari, and R. Watts, 1988, The economics of the relation between earnings changes and stock returns, Working paper (University of Rochester, Rochester, NY).

Bathke, A. and K. Lorek, 1984, The relationship between time-series models and the security market's expectation of quarterly earnings, The Accounting Review 59, 163-176.

Bernard, V., 1984, The use of market data and accounting data in hedging against consumer price inflation, Journal of Accounting Research 22, 445-466.

Bernard, V., 1987, Cross-sectional dependence and problems in inference in market-based accounting research, Journal of Accounting Research 25, 1-48.

Bernard, V. and J. Thomas, 1989, Post-earnings-announcement drift: Delayed price response or risk premium? Journal of Accounting Research, Suppl. 27, 1-36.

Brown, L., P. Griftin, R. Hagerman, and M. Zmijewski, 1987, An evaluation of alternative proxies for the market's assessment of unexpected earnings, Journal of Accounting and Economics 9, 159-194.

Brown, L.P. and M. Rozeff, 1979, Univariate time-series models of quarterly accounting earnings per share: A proposed model, Journal of Accounting Research 17, 179-189.

Brown, K.. W. Harlow, and S. Tinic, 1988, Risk aversion, uncertain information, and market efficiency, Journal of Financial Economics 21, 355-386.

Chambers. A. and S. Penman, 1984, Timeliness of reporting and the stock price reaction to earnings announcements, Journal of Accounting Research 21, 21-47.

Chari, V.. R. Jagannathan, and A. Ofer, 1988, Seasonalities in security returns: The case of earnings announcements, Journal of Financial Economics 21, 101-121.

Easton, P. and M. Zmijewski, 1989, Cross-sectional variation in the stock market response to the announcement of accounting earnings, Journal of Accounting and Economics 11, 117-142.

Fama, E. and J. MacBeth, 1973, Risk, return, and equilibrium: Empirical tests, Journal of Political Economy 38, 607-636. 
Foster, G., 1977, Quarterly accounting data: Time series properties and predictive-ability results, The Accounting Review 52, 1-21.

Foster, G., C. Olsen, and T. Shevlin, 1984, Earnings releases, anomalies, and the behavior of security returns, The Accounting Review 59, 574-603.

Freeman, R. and S. Tse, 1989, The multi-period information content of earnings announcements: Rational delayed reactions to earnings news, Journal of Accounting Research, Suppl. $27,49-79$.

Hand, J.R., 1990, A test of the extended functional fixation hypothesis, The Accounting Review $65,740-763$.

Holthausen, R., 1983, Abnormal returns following quarterly earnings announcements, in: Proceedings of the CRSP seminar on the analysis of security prices (University of Chicago, Chicago, IL) 37-59.

Jaffe, J.F., 1974, Special information and insider trading, Journal of Business 47, 410-428.

Joy, O.M., R. Litzenberger, and R. McEnally, 1977, The adjustment of stock prices to announcements of unanticipated changes in quarterly earnings, Journal of Accounting Research 15, 207-225.

Keim. D.B., 1989, Trading patterns, bid-ask spreads and estimated security returns: The case of common stocks at calendar turning points, Journal of Financial Economics 25, 75-98.

Kormendi, R. and R. Lipe, 1987, Earnings innovations, earnings persistence, and stock returns, Journal of Business 60, 323-346.

Marais, M.L., 1989, Discussion of post-earnings-announcement drift: Delayed price response or risk premium?, Journal of Accounting Research, Suppl. 27, 37-48.

Mendenhall, R., forthcoming, Evidence of possible underweighting of earnings-related information, Journal of Accounting Research.

O'Brien, P., 1988, Analysts' forecasts as earnings expectations. Journal of Accounting and Economics 10, 53-83.

Ou, J. and S. Penman, 1989a, Financial statement analysis and the prediction of stock returns, Journal of Accounting and Economics 11, 295-330.

Ou, J. and S. Penman, 1989b, Accounting measurement, price-earnings ratios, and the information content of security prices, Journal of Accounting Research, Suppl. 27, 111-144.

Poterba, J.M. and L.H. Summers, 1988, Mean reversion in stock prices: Evidence and implications, Journal of Financial Economics 21, 27-59.

Rendleman, R.J., Jr., C.P. Jones, and H.A. Latane, 1982, Empirical anomalies based on unexpected earnings and the importance of risk adjustments, Journal of Financial Economics 10. 269-287.

Rendleman, R.J., Jr., C.P. Jones, and H.A. Latane, 1987. Further insight into the standardized unexpected earnings anomaly: Size and serial correlation effects, The Financial Review 22, 131-144.

Watts, R.L., 1975, The time series behavior of quarterly earnings, Working paper (University of Newcastle, Newcastle, NSW).

Watts, R.L., 1978, Systematic 'abnormal' returns after quarterly earnings announcements, Journal of Financial Economics 6, 127-150.

Wiggins, J.B., 1990, Do misperceptions about the earnings process contribute to post-announcement drift, Working paper (Cornell University, Ithaca, NY). 